\title{
Still at the Center of it All; Novel Functions of the Oxidative Krebs Cycle
}

Ryan J. Mailloux*

Department of Biochemistry Memorial University of Newfoundland, St.John's ,Newfoundland A1B3X9, Canada

\begin{abstract}
The Krebs cycle is a universal metabolic cascade furnishing all organisms on Earth with the basic building blocks of life. Flux through the Krebs cycle is required to drive the production of the universal energy currency ATP. Carbon intermediates from the Krebs cycle also serve as precursors for the genesis of amino acids, lipids, and nucleotides. Considering that carbon in the Krebs cycle generates all the requisite ingredients that allow life to flourish it is easy to reconcile why it is found in all organisms. Although we have an eloquent understanding of the Krebs cycle and its function in relation to biochemistry and physiology, the basic tenets of this pathway are still being studied. This can be attributed to discoveries showing the Krebs cycle fulfills various other cellular functions including antioxidant defense, control of transcription, and cellular signaling. In the present article, I will discuss the novel functions of the Krebs cycle including its role in antioxidant defense, reactive oxygen species (ROS) production, and signaling. These functions are inherently related to its central function, carbon metabolism and mobilization of electrons for energy production or anabolic reactions. These novel Krebs cycle functions are influenced by the efficiency of nutrient metabolism and electron transfer reactions, two factors that are fundamental to the existence of life on Earth.
\end{abstract}

Keywords: Krebs cycle; Mitochondria; Oxidative phosphorylation; Lipids

\section{Introduction}

It is predicted that the Krebs cycle may be responsible for the emergence of life on Earth. The ancient origins of the Krebs cycle can be traced to acetogenic and methanogenic microbes which generate Krebs cycle intermediates by fixing carbon dioxide $\left(\mathrm{CO}_{2}\right)$ [1]. Acetogenesis and methanogenesis are processes by which $\mathrm{CO}_{2}$ is fixed in the presence of hydrogen gas $\left(\mathrm{H}_{2}\right)$ to produce acetate which is then enzymatically converted to pyruvic acid and oxaloacetic acid, key ingredients required to produce the basic building blocks of life [1]. The conversion of acetate into pyruvate and oxaloacetate relies on acetyl-CoA synthetase which produces acetyl-CoA from acetate and pyruvate carboxylase which produces oxaloacetate from pyruvate $[1,2]$. However in terms of biochemical origins production of acetate from $\mathrm{CO}_{2}$ and $\mathrm{H}_{2}$ can also proceed abiotically. It has been proposed that prebiotic genesis of acetate could have occurred naturally at alkaline hydrothermal vents which provides the requisite geochemistry for the genesis of the precursors molecules required for the evolution of life $[1,3]$. The exhalant from alkaline hydrothermal vents forms large spires consisting of tiny micro compartments composed of calcium magnesium carbonate $\sim 5 \mu \mathrm{M}$ thick containing sea water enriched with Fe-S and $\mathrm{Ni}-\mathrm{S}$ minerals, $\mathrm{CO}_{2}, \mathrm{H}_{2(\mathrm{~g})}, \mathrm{NH}_{3}$, and sulfur [3]. The sea water inside the micro compartments is alkaline $(\mathrm{pH} \sim 9)$ and maintained at $\sim 100^{\circ} \mathrm{C}$, ideal conditions that favor $\mathrm{CO}_{2}$ fixation and acetate production [3]. In addition, given the presence of sulfur and electron donating molecules it would have also been thermodynamically favorable for acetate to fix $\mathrm{CO}_{2}$ for the production of Krebs cycle intermediates [4]. The small size of the calcium magnesium carbonate micro compartments would have also encouraged the build-up of metabolites to high concentrations facilitating $\mathrm{CO}_{2}$ fixation and production of Krebs intermediates. With this in mind, it is easy to reconcile how elements of the Krebs cycle could have formed in the prebiotic environment which also explains the universality of this metabolic core on Earth.

In contrast to the reductive Krebs cycle, the evolutionarily modern Krebs cycle found in aerobic organisms oxidizes carbon for ATP production and anabolic reactions (Figure 1). The reversal of the Krebs cycle from a reductive pathway that fixes $\mathrm{CO}_{2}$ to an oxidative pathway that strips electrons from carbon liberating $\mathrm{CO}_{2}$ most likely occurred after the Great Oxygenation Event 2.2 billion years ago [5]. The incorporation of $\mathrm{O}_{2}$ into routine metabolism meant that organisms were able to conserve more energy from nutrient oxidation. Eventually the enzymatic machinery required for oxidative metabolism was compartmentalized in mitochondria which substantially enhanced energy conservation from nutrient oxidation culminating with the evolution of multicellular organisms [6]. Thus, $\mathrm{O}_{2}$ utilization meant that the Krebs cycle needed to be tailored from a metabolic cascade that uses electrons to fix carbon to a pathway that oxidizes nutrients and releases $\mathrm{CO}_{2}$ to liberate electrons for ATP production. The oxidative catabolism of organic acids in mitochondria was first described by Hans Krebs 75 years ago [7,8]. Although we have an appreciable understanding of the biochemistry of the Krebs cycle, its regulation, and role in human physiology we are still investigating the basic tenets of this metabolic pathway. This is simply due to new evidence that shows that the oxidative Krebs cycle participated in antioxidant defense, ROS homeostasis, intra- and intercellular signaling, and covalent modification of proteins. In addition, some Krebs cycle enzymes display pleiotropic functions which include roles in modulation of DNA stability and mRNA translation $[9,10]$. In the present review I will discuss emerging novel functions of the oxidative Krebs cycle and the relationship of these new functions to its classic function, nutrient metabolism and electron mobilization. Indeed, the newly described functions of the oxidative Krebs cycle are related, in general, to the efficiency of electron transfer reactions in mitochondria. These new functions will be discussed in the context of physiology, disease, and medicine. For clarity the Krebs cycle in this article will be referred to as the oxidative Krebs cycle. It is appropriate to add the term oxidative in front of Krebs cycle since it refers to the removal of

*Corresponding author: Ryan J. Mailloux, Department of Biochemistry Memorial University of Newfoundland, St.John's ,Newfoundland A1B3X9, Canada, Tel: +1613-562-5800; E-mail: rmaillou@uottawa.ca

Received May 04, 2015; Accepted May 13, 2015; Published May 16, 2015

Citation: Mailloux RJ (2015) Still at the Center of it All; Novel Functions of the Oxidative Krebs Cycle. Bioenergetics 4: 122. doi:10.4172/2167-7662.1000122

Copyright: @ 2015 Mailloux RJ. This is an open-access article distributed under the terms of the Creative Commons Attribution License, which permits unrestricted use, distribution, and reproduction in any medium, provided the original author and source are credited. 
electrons from carbon for the purpose of catabolism and anabolism which stands in stark contrast to the reductive Krebs cycle utilized by anaerobic organisms.

\section{The Oxidative Krebs cycle}

Catabolic reactions and the production of ATP by oxidative phosphorylation: In order to explore the novel roles the oxidative Krebs cycle fulfills it is first important examine its principle function, oxidation of carbon intermediates for ATP production and biosynthetic reactions. Carbon metabolism by the oxidative Krebs cycle has been reviewed numerous times over the years in extensive detail [11-14]. For our purposes here, I will summarize reactions in the oxidative Krebs cycle focusing on key enzymes that serve as important sites for control of Krebs cycle flux. The core of the oxidative Krebs cycle consists of 8 enzymes working in tandem to oxidize carbon intermediates (Figure 1). In the cycle there are key sites for regulation which mostly depends on the irreversible nature of certain enzymatic steps such as the reactions catalyzed by Pdh, Idh, and Odh $[11,15]$. However, other enzymes that catalyze reversible reactions, like Acn or Sdh, also serve as important control points for carbon flux. In fact, it can be argued that Sdh serves as an important bottle neck for the cycle considering it is a chief site for metabolic regulation, its substrate succinate is involved in signaling, and succinate is only metabolized by Sdh. These regulatory points serve an important purpose; determining if carbon in the oxidative Krebs cycle will be utilized for catabolic or anabolic reactions or be utilized for novel functions like signaling or covalent modification of proteins. During catabolic reactions, disparate nutrients in the form of monosaccharides, lipids, or amino acids are metabolized via distinct metabolic cascades to yield common intermediates; acetyl-CoA, 2-oxoglutarate, oxaloacetate, and fumarate which enter the oxidative Krebs cycle. The flux of carbon through the cycle is reliant on eight enzymes that work in tandem to systematically oxidize substrates (Figure 1a) [16]. The oxidative Krebs cycle can be subcategorized into two key phases; the $\mathrm{CO}_{2}$ evolving phase and the oxaloacetate regeneration phase. The number of $\mathrm{CO}_{2}, \mathrm{NADH}$, and $\mathrm{FADH}_{2}$ yielded during carbon oxidation by the Krebs cycle depends on the nutrient being metabolized (Figure 1a). On top of this series of eight enzymes other critical enzymes work directly outside the cycle to ensure that the requisite common intermediates are produced in sufficient quantities to prime the cycle (Figure 1a). These anaplerotic enzymes include pyruvate dehydrogenase (Pdh), pyruvate carboxylase (Pc), lactate dehydrogenase (Ldh), glutamate dehydrogenase (Gdh), aspartate aminotransferase (Aat), adenylosuccinate lyase (Asl), arginosuccinate lyase (Agl), $\beta$-oxidation enzymes, and ketone body degradation cascades which convert end products of glucose metabolism, amino acid, fatty acids, and purine nucleotide metabolism into common intermediates acetyl-CoA, oxaloacetate, 2-oxoglutarate, and fumarate [17-23]. Branched chain amino acid catabolism can also feed directly into the Krebs cycle forming glutamate, acetyl-CoA, succinyl-CoA, and/or acetoacetate [24]. Different combinations of anaplerotic enzymes are expressed in different tissues to meet nutrient and energy demands. For example, Agl is found mostly in hepatocytes where excess amino acids are oxidized and ammonia removed for elimination by the Urea cycle [25]. On the other hand $\beta$-oxidation enzymes are most heavily expressed in tissues that have high energy demands like skeletal muscle and cardiac tissue [26]. By contrast, brain tissue satisfies a vast majority of its anaplerotic demands via glucose metabolism with minor contributions from ketone bodies and fatty acids [27,28]. Modulation of anaplerotic enzymes is critical since they serve as important entry points for nutrients into the Krebs cycle. Most of these enzymes are modulated by allosteric regulators and covalent modifications. For instance Pdh is heavily regulated by its substrates and products and the availability of ADP [29]. It is also controlled by phosphorylation, sulfenylation, and potentially S-glutathionylation which are required to modulate its activity in response to fluctuations in mitochondrial energy metabolism, Krebs cycle flux, and reactive oxygen species (ROS) levels [30,31]. The first phase of the oxidative Krebs cycle is initiated by the condensation of acetyl-CoA with oxaloacetate producing citrate and $\mathrm{CoASH}$, a reaction catalyzed by citrate synthase (Cs) (Figure 1a) [32]. Citrate is then enzymatically converted by aconitase (Acn) through a cis-aconitate intermediate generating isocitrate [33]. The catalytic activity of Acn relies on a cubane iron sulfur cluster $\left(\mathrm{Fe}_{4}-\mathrm{S}_{4}\right)$ which binds citrate to eliminate hydroxyl from the $\mathrm{C}_{3}$ position [33]. Acn is an important site for regulation of the Krebs cycle since the $\mathrm{Fe}_{\mathrm{a}}$ of the Fe-S cluster is highly amenable to oxidation by a range of reactive oxygen species (ROS) including superoxide $\left(\mathrm{O}_{2}^{-\bullet}\right)$, hydrogen peroxide $\left(\mathrm{H}_{2} \mathrm{O}_{2}\right)$, and peroxynitrite (ONOO-) [34]. Although $\mathrm{Fe}-\mathrm{S}$ disassembly is often associated with oxidative stress and correlates strongly with development of various metabolic disorders, low grade $\mathrm{O}_{2} \bullet / \mathrm{H}_{2} \mathrm{O}_{2}$ production can also modulate Acn function in response to changes in mitochondrial nutrient metabolism and cellular demands [35]. Recent reports showing that cysteine residues that sit close to the active site of Acn can be modulated by redox signaling, in particular sulfenylation and S-glutathionylation, further illustrate the potential importance of ROS signaling in modulating Acn and Krebs cycle flux [36]. Isocitrate dehydrogenase (Idh) then oxidizes isocitrate in the presence of NAD+ or NADP+ generating 2-oxoglutarate [37]. Electron transfer to NAD $(\mathrm{P})^{+}$and production of NAD $(\mathrm{P}) \mathrm{H}$ is coupled to the evolution of $\mathrm{CO}_{2}$. Preference for either $\mathrm{NAD}^{+}$or $\mathrm{NADP}^{+}$is isoform dependent and in various tissues both isoforms can be found in mitochondria simultaneously [38-40]. Both isoforms fulfill drastically different roles in mitochondria with NAD+-Idh supporting oxidative phosphorylation and NADP+-Idh dedicated to supporting antioxidant defense and anabolic reactions (discussed below). The next enzyme, Odh, is required to metabolize 2-oxoglutarate in the presence of CoASH and $\mathrm{NAD}+$ forming the high energy intermediate succinyl-CoA, NADH, and $\mathrm{CO}_{2}$. Odh sits at a critical junction in the oxidative Krebs cycle to amino acid metabolism (Figure 1a). In addition, 2-oxoglutarate is a product of the glutamate-mediated transamination of carbon skeletons for the production of other amino acids (Figure 1a). Thus, 2-oxoglutarate metabolism is critical for the maintenance of amino acid homeostasis. Notably, 2-oxoglutarate fulfills a myriad of other functions including serving as an antioxidant and as an intercellular signaling molecule. These additional functions are discussed in more detail below. The second phase of the oxidative Krebs cycle begins with the conversion of succinyl-CoA to succinic acid which is catalyzed by succinyl-CoA synthetase (Scs) (Figure 1a). The thioester bond between the succinyl moiety and CoA is high energy allowing for coupling of hydrolysis to ATP or GTP formation (denoted as NTP in diagram for simplicity). Note coupling thioester linkage hydrolysis to ADP or GDP phosphorylation is isoform dependent. Importantly, succinyl-CoA can also be utilized to covalently modify proteins in mitochondria and throughout the cell via a process termed succinylation which is discussed in more detail below. Succinic acid is then oxidized by succinate dehydrogenase (Sdh) producing fumaric acid. The two electrons yielded from succinate oxidation are passed directly to ubiquinone (Q) through FAD and three Fe-S clusters [41]. Succinate metabolism is only driven by Sdh. Thus, Sdh serves as a "bottle neck" for control over flux through the oxidative Krebs cycle. Sdh is modulated by a number of allosteric regulators and redox modifications 
Citation: Mailloux RJ (2015) Still at the Center of it All; Novel Functions of the Oxidative Krebs Cycle. Bioenergetics 4: 122. doi:10.4172/21677662.1000122
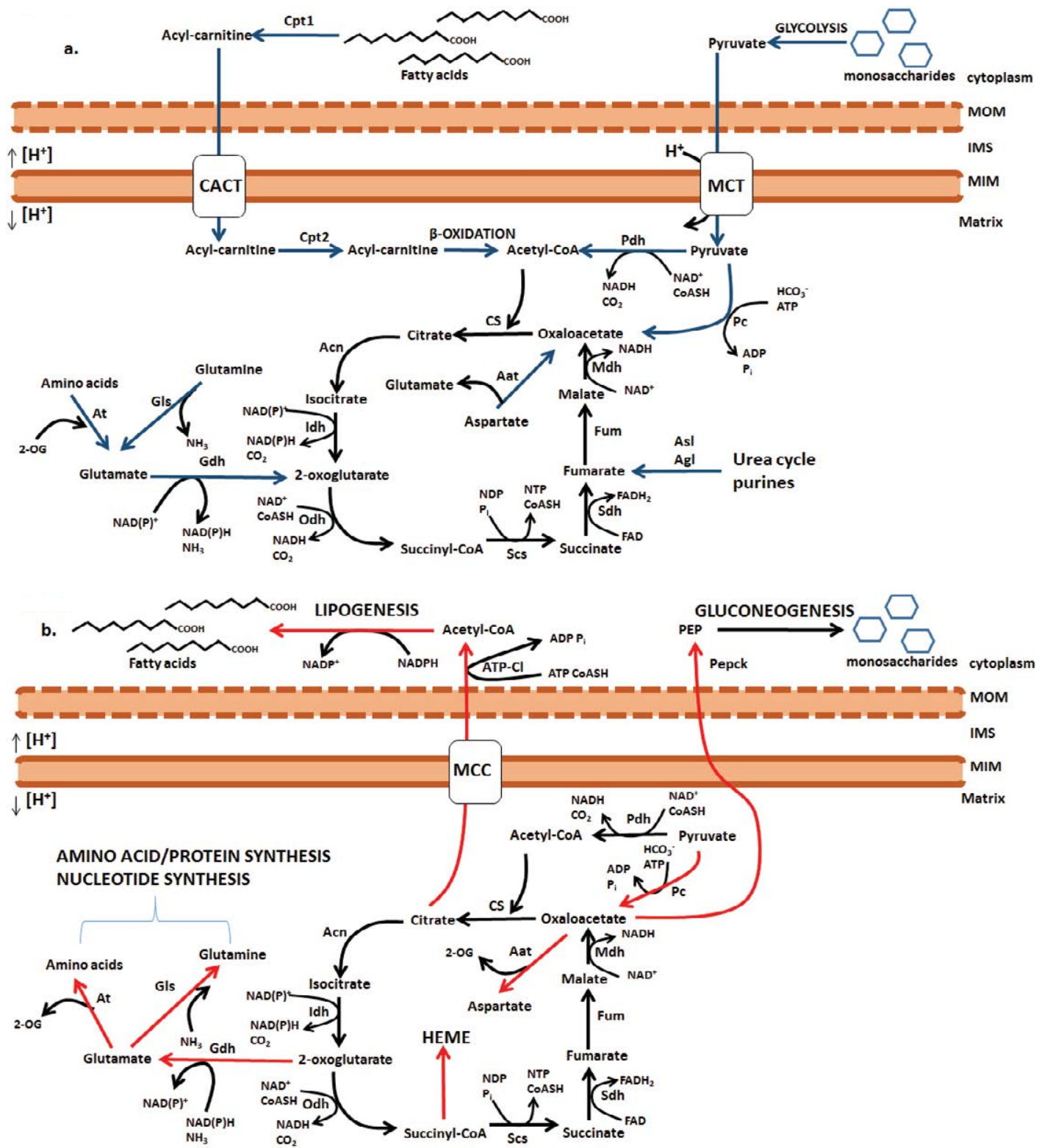

Figure 1: Catabolic and anabolic reactions of the oxidative Krebs cycle. a) Nutrients in the form of monosaccharides, lipids, amino acids, and nucleotides are metabolized by glycolysis, fatty acid oxidation, and various other cascades forming common metabolic intermediates acetyl-CoA, oxaloacetate, 2-oxoglutarate, and fumarate which enter the Krebs cycle for further oxidation. Prior to conversion to acetyl-CoA the end product of glycolysis pyruvate is transported into the matrix by monocarboxylate transporter (MCT). Note that conversion of pyruvate to acetyl-CoA is catalyzed by pyruvate dehydrogenase (Pdh) which couples pyruvate oxidation to NADH production and evolution of $\mathrm{CO}_{2}$. Pyruvate is also converted to oxaloacetate by pyruvate carboxylase (Pc). Fatty acid uptake by mitochondria is initiated by formation of acyl-carnitine, a reaction catalyzed by carnitine palmitoyl transferase $1(\mathrm{Cpt} 1)$. Acyl-carnitine is then taken up by mitochondria via the carnitine acyl-carnitine translocator (CACT) where, upon entering the matrix, acyl-carnitine is converted back to acyl-CoA by Cpt2 prior to being subjected to $\beta$-oxidation. Amino acids are deaminated generating glutamate which enters the Krebs cycle following removal of $\mathrm{NH}_{3}$ by glutamate dehydrogenase (Gdh), a reaction that is coupled to $\mathrm{NAD}(\mathrm{P}) \mathrm{H}$ production. Aspartic acid also enters the Krebs cycle at the level of oxaloacetate, a reaction that is catalyzed asparate aminotransferase (Aat). Purine metabolism and urea cycle function also provide fumarate via the action of adenylosuccinate lyase (Asl) and arginosuccinate lyase (Agl). Upon entry into the oxidative Krebs cycle carbon is oxidized to yield NADH and FADH2 at various steps. Production of NADH at the levels of Idh and Odh is coupled to the release of CO2. Electrons from NADH and FADH2 are then mobilized by Complex I and Sdh (Complex II) and passed to $\mathrm{O} 2$ at the level of Complex IV. Electron transfer is coupled to the establishment of a transmembrane potential of protons which is tapped by Complex $V$ for the production of ATP. b) For anabolic reactions, carbon from the Krebs cycle is diverted towards the biosynthesis of various building blocks required for the production of biological macromolecules (membranes, proteins, and DNA). Citrate is exported into the cytosol by mitochondrial citrate carrier (MCC) where it is cleaved by ATP-citrate lyase (ATP-c1) producing acetyl-CoA, the starting material for lipogenesis. 2-oxoglutarate can be diverted to serve as an ammonia acceptor generating glutamate. Glutamate is then utilized to generate glutamine via glutamine synthase (Gls) or can be utilized for the genesis of other amino acids including aspartic acid at the level of oxaloacetate. Amino acids yielded from Krebs cycle intermediates are then utilized for protein biosynthesis. Glutamate, glutamine, and aspartate are also utilized for nucleotide production. Succinyl-CoA is utilized for heme biosynthesis and oxaloacetate can be committed to gluconeogenesis and glucose production by phosphoenolpyruvate carboxykinase (Pepck). At; aminotransferase, Cs; citrate synthase, Acn; aconitase, Idh; isocitrate dehydrogenase, Odh; 2-oxoglutarate dehydrogenase, Scs; succinyl-CoA synthetase, Sdh; succinate dehydrogenase, Fum; fumarase, Mdh; malate dehydrogenase, 2-OG; 2-oxoglutarate. 
including S-glutathionylation, sulfenylation, and covalent modification by 4-hydroxy-2-nonenal [33]. Modulation of Sdh via these regulatory mechanisms can prompt accumulation of succinic acid and succinyl$\mathrm{CoA}$, two important signaling molecules [42]. In addition, regulation of Sdh also controls the amount of superoxide $\left.\left(\mathrm{O}_{2} \cdot\right)^{-}\right)$being generated which, following dismutation to hydrogen peroxide $\left(\mathrm{H}_{2} \mathrm{O}_{2}\right)$, serves as an important signaling molecule as well. The importance of Sdh in signaling the "state" of Krebs cycle flux to the rest of the cell and other cells is discussed below. The fumarate yielded from the action of Sdh is then hydrated by fumarase (Fum) producing malic acid which is then subsequently oxidized by malate dehydrogenase (Mdh) to generate oxaloacetate and $\mathrm{NADH}$ completing the cycle.

Oxidative phosphorylation is initiated by oxidation of NADH generated by Krebs cycle enzymes by Complex I [43]. The liberated electrons are then systematically passed through a series of prosthetic groups and cofactors that are strategically positioned according to increasing electron affinity inside and in between the individual respiratory complexes to the terminal electron acceptor di-oxygen $\left(\mathrm{O}_{2}\right)$ at Complex IV [44]. Favorable electron transfer reactions are coupled to the movement of protons through Complexes I, III, and IV, respectively, which establishes a transmembrane electron chemical potential of protons $\left(\Delta \mu_{\mathrm{m}}\right)$ which is utilized by Complex $\mathrm{V}$ to drive ATP synthesis completing the oxidative phosphorylation chain [45]. Thus, catabolism in the oxidative Krebs cycle basically involves removal of electrons from carbon and the subsequent use of electron movement for the production of the universal energy currency ATP. Note that since the focus of this article is on the oxidative Krebs cycle details on electron transfer through the respiratory complexes, proton pumping mechanisms, and the regulation of electron flow and ATP production have been omitted. For detailed information on oxidative phosphorylation and electron transfer through the complexes the reader is encouraged to consult the following reviews [16,34,44,45].

Anabolic reactions; production of lipids, amino acids, nucleotides, and other macromolecular structures: The oxidative Krebs cycle is also responsible for furnishing cells with the requisite carbon precursors for the biosynthesis of amino acids, lipids, and nucleotides (Figure 1b). Citrate is utilized for the biosynthesis of fatty acids while 2-oxoglutarate and oxaloacetate can be diverted for the production of glutamate and aspartate which are utilized to generate other nonessential amino acids such as glutamine and asparagine. Asparate, glutamine, and glutamate are also required for the biosynthesis of purine and pyrimidine ribonucleotides [46]. Ribonucleotide production generates significant amounts of fumaric acid which can re-enter the oxidative Krebs cycle for further metabolism. Succinyl-CoA serves as an important precursor for heme biosynthesis and oxaloacetate can be utilized to drive gluconeogenesis and glucose production [47]. Note that the biosynthesis of amino acids, nucleotides and lipids and the subsequent use of these molecules to make macromolecular structures (DNA, membranes, and proteins) is very energetically costly and requires a substantial amount of NADPH and ATP. Thus, there is a tight link between the energy state of the cell and whether or not catabolic and anabolic reactions will occur. It is also important to point out that tissues have different anabolic signatures which are highly dependent on anabolic gene expression patterns. For example, gluconeogenic reactions principally take place in the liver and kidney and have been reported to occur to a lesser extent in skeletal muscle $[48,49]$. Fatty acid biosynthesis on the other hand is more prevalent being found in liver, kidney, white and brown adipose and has been reported to occur in brain tissue, principally astrocytes, and skeletal muscle $[50,51]$. As indicated above, de novo biosynthesis of the basic building blocks of life requires a substantial energy input in the form of ATP and NADPH. Thus, whether or not intermediates in the oxidative Krebs cycle will be diverted towards biosynthesis is inherently related to the energy state of the cell. The NADP pool is for the most part maintained in a reduced state with NADPH dominating in concentration over NADP (NADPH/NADP is 100) and is thus not a regulatory determinant for diversion of carbon away from the Krebs cycle for biosynthesis [52]. The efficiency of NADH oxidation however, can dictate whether or not carbon intermediates in the Krebs cycle will be utilized for anabolic reactions. Increased NADH concentrations can slow the oxidative Krebs cycle via allosteric inhibition of Pdh, Odh, Scs, and Acn allowing for the accumulation of intermediates and their subsequent diversion towards biosynthesis. The use of citrate for fatty acid biosynthesis, to a certain degree, functions in the manner. A slowing of the Krebs cycle due to diminished NADH oxidation leads to citrate accumulation in the matrix [53]. Once the concentrations are sufficiently elevated citrate is pumped out of mitochondria by mitochondrial citrate carrier (MCC) and cleaved by ATP-citrate lyase generating oxaloacetate and acetyl-CoA (Figure 1b) [54]. The acetyl$\mathrm{CoA}$ is then diverted towards de novo lipogenesis. Redox signaling mechanisms and ROS, specifically $\mathrm{O}_{2}{ }^{\bullet}$, peroxynitrite, and $\mathrm{H}_{2} \mathrm{O}_{2}$ can converge on Acn and disable its activity [35]. Redox signaling mechanisms such as S-glutathionylation can inhibit Acn activity via modification of critical thiols required to drive enzyme catalysis [36]. These signaling mechanisms can amplify citrate accumulation by inhibiting Acn function. Prolonged inhibition of Acn by ROS or overt changes in redox environment during oxidative stress or environmental contaminant toxicity is also associated with development of metabolic disorders such as obesity and fatty liver disease (hepatic steaotosis) [55]. Another potent modulator of flux is acetyl-CoA which feeds back to inhibit Pdh [56]. Accumulation of acetyl-CoA is inherently related the 1) quantity of oxaloacetate available for citrate production and 2) the acetyl-CoA buffering capacity of carnitine acetyltransferase (CrAT) which converts excess acetyl-CoA into acetyl-carnitine [18]. Another key regulatory mechanism would also be the amount of ATP. However, the concentration of ATP varies at most 10-20\% in a resting versus active cell (e.g. skeletal muscle at rest and exercise) [57]. , despite this small variation in absolute cellular ATP levels between different energy states it still serves as an allosteric regulator. Indeed, small changes in cellular ATP levels can inhibit various glycolytic and oxidative Krebs cycle enzymes [12,58]. However the true adenosine regulator for carbon flux in catabolic and anabolic reactions is AMP. A modest change in ATP levels can lead to an $\sim 40-50 \%$ change in cellular AMP [59]. AMP does serve as direct allosteric modulator but most of its effects are mediated through AMP kinase (AMPK) [60]. Low AMP levels indicate that there is sufficient ATP that can be utilized for biosynthetic reactions. However, elevation of AMP results in either direct activation of catabolic enzymes or activation of AMPK which phosphorylates various proteins and enzymes involved in ATP production. Generally, AMPK phosphorylates and inhibits biosynthetic enzymes that expend ATP for anabolic reactions. For example acetylCoA carboxylase, which is required to initiate de novo lipogenesis, is inhibited by AMPK-mediated phosphorylation [60]. Adenylate kinase (AK) is largely responsible for modulating the concentration of cellular AMP. AK mediated formation of AMP requires two ADP molecules, with one ADP being utilized to phosphorylate the other generating ATP and AMP [61]. AK activity and expression is often associated with skeletal muscle but other tissues also express AK [61]. In fact, there are three $\mathrm{AK}$ isoforms, $\mathrm{AK} 1, \mathrm{AK} 2$, and $\mathrm{AK} 3$ [61]. $\mathrm{AK} 1$ is predominantly expressed in skeletal muscle however; other tissues such as heart, kidney, lung, stomach and brain also express this isoform [61]. AK2 
seems to be expressed only in liver and kidney while AK3 is found in most tissues [61]. Thus, it would seem that most tissues are endowed with the capacity to utilize AMP as a fuel gauge for the modulation of catabolic and anabolic pathways. In addition, a number of regulatory mechanisms are utilized to dictate carbon flux in the oxidative Krebs cycle and whether or not intermediates will be utilized for ATP production or biosynthetic reactions.

\section{$\mathrm{O}_{2}{ }^{-}$and $\mathrm{H}_{2} \mathrm{O}_{2}$ production and degradation}

Mitochondria are well known to fulfill a number of functions which are inherently related to its chief function; coupling electron transfer reactions to the establishment of a proton motive force for ATP production and biosynthetic reactions. However, electron transfer reactions are not perfectly coupled to the reduction of $\mathrm{O}_{2}$. Electrons removed from nutrients and transferred through the respiratory complexes can prematurely reduce $\mathrm{O}_{2}$ generating $\mathrm{O}_{2} \cdot$. Genesis of oxyradicals by mitochondria is an inherent consequence of the unique chemistry of $\mathrm{O}_{2}$ [62]. The monovalent reduction of $\mathrm{O}_{2}$ can occur at various levels of carbon metabolism in mitochondria. Univalent reduction by either Krebs cycle enzymes or respiratory complexes is dependent on several factors including the reactivity of the electron donating center, the distance between the one electron donor and $\mathrm{O}_{2}$, and the response of the electron donor and acceptor to changes in charge [16]. For the most part enzymes that harbor flavin adenine dinucleotide (FAD) or flavin mononucleotide (FMN) prosthetic groups can partake in $\mathrm{O}_{2}{ }^{-}$or $\mathrm{H}_{2} \mathrm{O}_{2}$ production [16]. Flavins can produce either $\mathrm{O}_{2}{ }^{-}$or $\mathrm{H}_{2} \mathrm{O}_{2}$ which is related to the production of flavin radical, flavin hydroperoxide, or flavin ion intermediates which generate either $\mathrm{O}_{2}{ }^{-}$and/or $\mathrm{H}_{2} \mathrm{O}_{2}$ at variable rates [63]. The rate of $\mathrm{O}_{2}{ }^{-}$or $\mathrm{H}_{2} \mathrm{O}_{2}$ production can also be accentuated by the surrounding protein microenvironment [63]. Although flavins can produce either $\mathrm{O}_{2}{ }^{-}$or $\mathrm{H}_{2} \mathrm{O}_{2} \mathrm{O}_{2}{ }^{-}$is often considered the proximal ROS species in mitochondria. Following its production, it is rapidly dismutated to $\mathrm{H}_{2} \mathrm{O}_{2}$ by superoxide dismutase (SOD). $\mathrm{H}_{2} \mathrm{O}_{2}$ can then be further metabolized by a number of $\mathrm{H}_{2} \mathrm{O}_{2}$ degrading antioxidant enzymes including glutathione and peroxiredoxin systems [64].

ROS production by mitochondria was once viewed as the "price we pay" for relying on the oxidative properties of $\mathrm{O}_{2}$ to drive ATP production. This has been dubbed the molecular oxygen paradox considering aerobic organisms rely on $\mathrm{O}_{2}$ for energy metabolism but are constantly being traumatized by its oxyradical chemistry [65]. It is true that at sufficient quantities $\mathrm{O}_{2}{ }^{-}$or $\mathrm{H}_{2} \mathrm{O}_{2}$ can damage cell constituents directly with the former disassembling $\mathrm{Fe}-\mathrm{S}$ clusters and the latter oxidized protein cysteine thiols [66]. Both $\mathrm{O}_{2}{ }^{-}$or $\mathrm{H}_{2} \mathrm{O}_{2}$ can also give rise to the dreaded hydroxyl radical $\left(\mathrm{OH}^{\bullet}\right)$ which can damage various biological molecules [67]. However, at low amounts $\mathrm{O}_{2}{ }^{-}$or $\mathrm{H}_{2} \mathrm{O}_{2}$ fulfill important signaling functions in the cell $[35,68] . \mathrm{O}_{2}{ }^{\circ-}$ can serve as a signaling molecule via the disassembly of Fe-S clusters [69]. The signaling properties of $\mathrm{O}_{2}{ }^{-}$can be best exemplified by the SoxR transcriptional regulator in bacteria, which is activated following the $\mathrm{O}_{2}{ }^{-}$mediated disassembly of an $\mathrm{Fe}-\mathrm{S}$ cluster [69]. $\mathrm{H}_{2} \mathrm{O}_{2}$ is viewed as one of the most important ROS involved in signaling. This is by virtue of its longer half-life, capacity to diffuse through membranes, and, most importantly, ability to reversibly oxidize protein cysteine thiols altering protein function [66]. In addition, $\mathrm{H}_{2} \mathrm{O}_{2}$ signaling cross talks with other cell signaling cascades including phosphorylation and acetylation [70,71]. Various mitochondrial enzymes are known to be modulated by $\mathrm{H}_{2} \mathrm{O}_{2}$ including Krebs cycle enzymes and respiratory complexes which plays a part in modulating carbon flux and oxidative phosphorylation in response to changing energy demands and nutrient metabolism efficiency [66]. Thus, $\mathrm{O}_{2}{ }^{\bullet}$ or $\mathrm{H}_{2} \mathrm{O}_{2}$ are not unfortunate by products of respiration but rather key ingredients required to fine tune mitochondrial metabolism, a dichotomy referred to as mitohormesis [72]. In order to take advantage of the rapid signaling properties of $\mathrm{O}_{2}{ }^{\bullet}$ or $\mathrm{H}_{2} \mathrm{O}_{2}$ whilst avoiding its toxicity, mitochondria must control the production and degradation of either molecule.

\section{$\mathrm{O}_{2}{ }^{--}$and $\mathrm{H}_{2} \mathrm{O}_{2}$ production in the Krebs cycle}

Complex I and III of the respiratory chain are considered the principle sources of $\mathrm{O}_{2}{ }^{\bullet-} \mathrm{H}_{2} \mathrm{O}_{2}$ in mitochondria [73]. Blockage of electron transfer results in the over reduction of the respiratory complexes which hyperpolarizes the mitochondrial inner membrane resulting in increased $\mathrm{O}_{2}{ }^{-/} \mathrm{H}_{2} \mathrm{O}_{2}$ production [73]. However, recent research efforts have been able to show that Krebs cycle enzymes, specifically Odh, Pdh, and Sdh are also quantitatively significant sources of $\mathrm{O}_{2}{ }^{-/} \mathrm{H}_{2} \mathrm{O}_{2}[18,43,74,75]$. Whether or not $\mathrm{Odh}$, Pdh, and Sdh are significant sources of $\mathrm{O}_{2}{ }^{-/} \mathrm{H}_{2} \mathrm{O}_{2}$ is highly dependent on which nutrient is being metabolized. For instance, Odh and Pdh produce far more $\mathrm{O}_{2}{ }^{\bullet-} \mathrm{H}_{2} \mathrm{O}_{2}$ than Complex I and Sdh when nutrients, that generate large amounts of NADH are being metabolized [43]. On the other hand Sdh generates $\mathrm{O}_{2}{ }^{-/} \mathrm{H}_{2} \mathrm{O}_{2}$ during succinate metabolism but can also produce significant amounts via reverse electron transfer (RET) from the Q pool [43]. Indeed, various nutrients such as proline, glycerol-3-phosphate, and dihydroorotate, by pass Complex I and feed electrons directly into the Q pool [16]. These electrons can then be transferred to Complex III or, depending on the state of the respiratory chain and the efficiency of forward electron transfer, can be moved to Sdh generating $\mathrm{O}_{2}{ }^{-1} \mathrm{H}_{2} \mathrm{O}_{2}$ [43]. The observation that $\mathrm{O}_{2}{ }^{-/} \mathrm{H}_{2} \mathrm{O}_{2}$ production in mitochondria from different sites is highly dependent on genesis of either NADH or ubiquinol $\left(\mathrm{QH}_{2}\right)$ has led to the suggestion that sites of mitochondrial $\mathrm{O}_{2}{ }^{--} \mathrm{H}_{2} \mathrm{O}_{2}$ production can be subcategorized into two isopotential groups; $\mathrm{NADH} / \mathrm{NAD}$ and $\mathrm{QH}_{2} / \mathrm{Q}$ isopotential groups [16,43]. The genesis of either $\mathrm{NADH}$ or $\mathrm{QH}_{2}$ or a combination of both is highly dependent on the nutrient being catabolized. Thus, production of $\mathrm{O}_{2}{ }^{-/} \mathrm{H}_{2} \mathrm{O}_{2}$ is site dependent redox status of either isopotential group which is influenced by nutrient type, nutrient metabolism efficiency, and mitochondrial redox poise. The $\mathrm{NADH} / \mathrm{NAD}$ isopotential group is comprised of Odh, Pdh, Bckdh, and Complex I [43]. The most important sources of $\mathrm{O}_{2}{ }^{-1 /} \mathrm{H}_{2} \mathrm{O}_{2}$ in this isopotential group are Odh and Pdh [43]. Production of $\mathrm{O}_{2}{ }^{-1} \mathrm{H}_{2} \mathrm{O}_{2}$ by Odh and Pdh has been attributed to its FAD prosthetic group located in the $\mathrm{E}_{3}$ subunit of the enzyme complex [76]. It is also worth noting that the FAD prosthetic group in Odh and most likely Pdh produces a mixture of $\mathrm{O}_{2}{ }^{-}$and $\mathrm{H}_{2} \mathrm{O}_{2}$ with the latter dominating over the former [77]. The most intriguing aspect about Odh and Pdh serving as $\mathrm{O}_{2}^{-1}$ $\mathrm{H}_{2} \mathrm{O}_{2}$ emission sites is that both enzyme complexes sit at important intersections of the oxidative Krebs cycle; Odh provides a direct link to amino acid anabolism and catabolism while Pdh is the entry of point for pyruvic acid, the end product of glycolysis, into the Krebs cycle. Both Odh and Pdh are tightly modulated by allosteric regulators and covalent modifications which can influence not only enzyme activity but also $\mathrm{O}_{2}{ }^{\bullet-/} \mathrm{H}_{2} \mathrm{O}_{2}$ emission. For instance, $\mathrm{O}_{2}{ }^{\bullet-/} \mathrm{H}_{2} \mathrm{O}_{2}$ production is highly responsive to $\mathrm{NADH} / \mathrm{NAD}$ [78]. NAD can become limiting in mitochondria considering the NAD/NADH ratio is maintained at $\sim 8$ due to the Krebs cycle (This is in contrast to the cytosol where NAD/ NADH is 100) [79]. Since NAD is normally superior in concentration to NADH, it could be assumed that blockage or slowing of Complex I activity would drive up the concentration of $\mathrm{NADH}$, a negative allosteric regulator of Odh and $\mathrm{Pdh}$, which would increase $\mathrm{O}_{2}{ }^{-{ }^{-}} \mathrm{H}_{2} \mathrm{O}$ emission [79]. Thus, it is probable that inhibition of Complex I is responsible for the increase in $\mathrm{O}_{2}{ }^{\bullet-} \mathrm{H}_{2} \mathrm{O}_{2}$ production by Odh and $\mathrm{Pdh}$ 
as found by Quinlan and colleagues [43]. Intriguingly, Cortassa et al recently found that $\mathrm{NADH} / \mathrm{NAD}$ changes temporally in response to fluctuations in ADP levels which correlates strongly with 1) the overall redox state of mitochondria (e.g. amount of reduced glutathione $(\mathrm{GSH})$ ) and 2) changes in $\mathrm{O}_{2}{ }^{-/} / \mathrm{H}_{2} \mathrm{O}_{2}$ [80]. Introduction of a small amount of ADP to isolated mitochondria induces a sharp decline in both $\mathrm{NAD}(\mathrm{P}) \mathrm{H}$ and $\mathrm{O}_{2}{ }^{\bullet-} \mathrm{H}_{2} \mathrm{O}_{2}$ indicating that $\mathrm{O}_{2}{ }^{\bullet-} \mathrm{H}_{2} \mathrm{O}_{2}$ production is sensitive to changes in NADH which is responsive to ADP availability, a major modulator of nutrient metabolism efficiency in mitochondria [80]. Thus, it is entirely probable that emission of $\mathrm{O}_{2}{ }^{-/} \mathrm{H}_{2} \mathrm{O}_{2}$ from Odh or Pdh serve a signal that not only fine tunes mitochondrial metabolism but also conveys the state of nutrient oxidation in mitochondria to the rest of the cell. Considering that Odh and Pdh sit at critical junctions in nutrient metabolism and Krebs cycle flux, this would make both enzymes ideal signaling platforms. Another intriguing aspect of Odh and $\mathrm{Pdh}$ is that both enzymes are deactivated by $\mathrm{H}_{2} \mathrm{O}_{2}[81,82] . \mathrm{H}_{2} \mathrm{O}_{2}$ deactivates both enzyme complexes by oxidizing vicinal thiols $(\mathrm{SH})$ on dihydrolipoamide on the $\mathrm{E}_{2}$ subunit forming sulfenic acid ( $\mathrm{SOH}$ [ [83]. Not only does this deactivates that enzyme complex but most likely also prevents the further reduction of FAD curtailing further $\mathrm{O}_{2}{ }^{-/} \mathrm{H}_{2} \mathrm{O}_{2}$ production. Thus, in a negative feedback loop $\mathrm{O}_{2}{ }^{\bullet-} \mathrm{H}_{2} \mathrm{O}_{2}$ can regulate its own production by blocking electron passage from dihydrolipoamide to FAD. This type of regulation would also be crucial since it would prevent a sustained or prolonged production of $\mathrm{O}_{2} \cdot{ }^{\bullet-} \mathrm{H}_{2} \mathrm{O}_{2}$ which could be potentially dangerous. Hence, a negative feedback loop is ideal considering it would allow rapid spatiotemporal pulsing of $\mathrm{O}_{2}^{\bullet-1}$ $\mathrm{H}_{2} \mathrm{O}_{2}$ from mitochondria in response to changes in energy demands and nutrient oxidation efficiency. Indeed, it has been shown that $\mathrm{O}_{2}^{\bullet-1}$ $\mathrm{H}_{2} \mathrm{O}_{2}$ production by mitochondria does pulse over time in response to fluctuations in ADP availability and redox environment [80]. However, even a $\mathrm{O}_{2}{ }^{\bullet-} \mathrm{H}_{2} \mathrm{O}_{2}$ negative feedback loop can be dangerous since $\mathrm{H}_{2} \mathrm{O}_{2}$ can irreversibly oxidize $\mathrm{SOH}$ to sulfenic $\left(\mathrm{SO}_{2} \mathrm{H}\right)$ and sulfonic acids $\left(\mathrm{SO}_{3} \mathrm{H}\right)$ [83]. To prevent over-oxidation, $\mathrm{SOH}$ is conjugated to $\mathrm{GSH}$ forming a protein glutathione mixed disulfide [84]. Addition of this moiety to the $\mathrm{SOH}$ group on dihydrolipoamide effectively protects from further oxidation. Moreover, S-glutathionylation can be reversed by thiol oxidoreductase glutaredoxin-2 (Grx2) which reactivates the enzyme complex [34]. It is important to point out that only Odh has been found to be reversibly S-glutathionylated however; recent indirect evidence would suggest Pdh is modulated by a similar mechanism [30]. Thus, regulation of $\mathrm{O}_{2}{ }^{-/} \mathrm{H}_{2} \mathrm{O}_{2}$ genesis by $\mathrm{Odh}$ and $\mathrm{Pdh}$ depends on vicinal thiol oxidation and followed by S-glutathionylation, a reversible signaling mechanism akin to phosphorylation and highly responsive to changes in redox environment.

\section{Krebs cycle in antioxidant defense}

Ground state $\mathrm{O}_{2}$ has two unpaired electrons in its outer most antibonding orbitals classifying it as a free radical. In addition, singlet electron reduction of $\mathrm{O}_{2}$ to $\mathrm{H}_{2} \mathrm{O}$ results in the formation of a series of reactive oxygen intermediates including $\mathrm{O}_{2}{ }^{\bullet}, \mathrm{H}_{2} \mathrm{O}_{2}$, and $\mathrm{OH}^{\bullet}[62,85]$. Thus, given its potentially damaging nature, antioxidant systems had to co evolve with $\mathrm{O}_{2}$ utilizing biological systems. Antioxidant systems form the main barrier against the potentially noxious properties of $\mathrm{O}_{2}$ and its reactive intermediates. Various redundant systems localized throughout the cell are employed to quench various free radical intermediates by either direct quenching of free radical centers or indirectly via prevention of free radical production. In mitochondria MnSOD is responsible for the dismutation of $\mathrm{O}_{2}{ }^{\bullet}$ while $\mathrm{H}_{2} \mathrm{O}_{2}$ is quenched by glutathione peroxidase $(\mathrm{GPx})$ and glutathione reductase (GR). In this system two GSH molecules are fixed by GPx to sequester $\mathrm{H}_{2} \mathrm{O}_{2}$ which yields oxidized glutathione (GSSG) [64]. The peroxiredoxin system (Prx) also plays an important role in quenching $\mathrm{H}_{2} \mathrm{O}_{2}$ [86]. The N-terminal peroxidatic cysteine of Prx is oxidized directly by $\mathrm{H}_{2} \mathrm{O}_{2}$ forming $\mathrm{SOH}$ which then reacts with a resolving cysteine thiol forming a disulfide bridge [86]. The disulfide bond is then reduced by mitochondrial thioredoxin $2(\operatorname{Trx} 2)$ and the disulfide bond on $\operatorname{Trx} 2$ is reduced by thioredoxin reductase (TrxR) [86]. Both the GSH and Prx system are highly efficient at removing $\mathrm{H}_{2} \mathrm{O}_{2}$. Details surrounding the efficiency of $\mathrm{H}_{2} \mathrm{O}_{2}$ quenching and the different isozymes have been recently reviewed in $[64,87]$. In addition, the consequences of knocking out elements of these systems can either result in extreme sensitivity to bursts in ROS or embryonic lethality $[64,88]$.

For our purposes in this review we will focus on the key reductive ingredient required to rejuvenate the antioxidant power of these systems, NADPH. NADPH only differs from NADH by a phosphate located on 2' carbon of the adenine nucleotide. However, this phosphate "earmarks" the nicotinamide nucleotide for anabolic reactions and antioxidant defense rather than catabolic reactions. NADPH provides the requisite reductive power required to drive the restoration of antioxidant properties of GSH and Prx. In the case of the former, GR utilizes NADPH to reduce the disulfide bonds in GSSG providing two GSH [89]. For Prx, NADPH is utilized by thioredoxin reductase to reduce the disulfide bridges formed on Trx2 [90]. A number of enzymes have been shown to generate NADPH in mitochondria including Idh, malic enzyme (Me), energy liberating transhydrogenase (Elth) and Gdh [37]. These five enzymes are expressed at different amounts in various tissues in response to variations in nutrient metabolism and thus occur in different combinations in the matrix of mitochondria [37]. Importantly though these enzymes provide a direct link between nutrient metabolism and antioxidant defense. Idh is often viewed as the most important in the provision of NADPH in the mitochondrial environment. There are two NADP-Idh isozymes, Idh1 which is found in the cytosol and Idh2 in the matrix [91,92]. Knock-out studies have shown that both enzymes play important roles in the maintenance of the NADPH pool and antioxidant defense [92,93]. In particular, loss of Idh2 in mitochondria leads to a significant depletion of the NADPH pool and loss of the mitochondrion's capacity to fend oxidative stress [92]. Variations in genes encoding Idh1 and Idh2 have also been associated with development of various human cancers including gliomas and acute myeloid leukemia [91]. It has been reported that Idh 1 or Idh 2 genes are mutated in more than $75 \%$ of gliomas and secondary glioblastoma [91]. In most cases the gene variants involve single amino acid substitutions. In the case of Idh2 typically Arg140 is substituted for Lys, Met, Gly, or Trp and Arg172 is substituted for Gln or $\operatorname{Trp}$ [91]. These variations in gene sequence alter the normal activity of Idh2 where NADPH is produced in high amounts. Also, a second product 2-hydroxyglutarate, is formed instead of 2-oxoglutarate [94]. Interestingly, formation of 2-hydroxyglutarate by Idh2 requires 2-oxoglutarate and NADPH as a substrate [94]. Knock out of Idh2 also prevents cancer development and 2-hydroxyglutarate has been suggested to serve as a potential biomarker for early detection of certain types of cancer [95]. It is now appreciated that fundamental alterations in oxidative Krebs cycle flux is inherently related to the development of cancer where metabolic pathways are tailored to meet the demands of a rapidly dividing system [96]. One of these many changes occurs at the level of NADPH metabolism which provides the requisite reductive power to rejuvenate antioxidant systems.

Another potentially important antioxidant property of the oxidative Krebs cycle is the role of $a$-keto acids, in particular 2-oxoglutarate and pyruvate, in quenching $\mathrm{H}_{2} \mathrm{O}_{2}$ [97]. Various studies have shown that both metabolites can spontaneously react with $\mathrm{H}_{2} \mathrm{O}_{2}$ [97-99]. In addition, 
a-keto acid supplementation has been shown to curtail mitochondrial permeability transition pore opening, protect from ischemiareperfusion injury, prevent apoptosis and oxidative damage, and ameliorate heavy metal toxicity [100-102]. The mechanism by which either $a$-keto acid spontaneously quenches $\mathrm{H}_{2} \mathrm{O}_{2}$ involves two steps. In the first step, $\mathrm{H}_{2} \mathrm{O}_{2}$ nucleophilically attacks the a-keto carbon in the metabolite yielding a perhydroxyl intermediate [99]. Then through a series of electron transfers within the carbon skeleton the perhydroxyl intermediate is decarboxylated [99]. The spontaneous $\mathrm{H}_{2} \mathrm{O}_{2}$ mediated decarboxylation of 2-oxoglutarate and pyruvate generates succinate and acetate, respectively, which can then re-enter the oxidative Krebs cycle. The caveat of this mechanism and the potential use of oxidative Krebs cycle intermediates in the quenching of $\mathrm{H}_{2} \mathrm{O}_{2}$ stems from the reactivity of a-keto acids with $\mathrm{H}_{2} \mathrm{O}_{2}$. In comparison to the $\mathrm{GSH}$ and Prx systems, which quench $\mathrm{H}_{2} \mathrm{O}_{2}$ at a rate of $\kappa \sim 10^{5}-10^{7} \mathrm{M}^{-1} \mathrm{~s}^{-1}$, pyruvic acid only reacts with $\mathrm{H}_{2} \mathrm{O}_{2}$ at a rate of $\kappa=2.2 \mathrm{M}^{-1} \mathrm{~s}^{-1}$ [87]. In addition, GSH is highly concentrated in mitochondria $(\sim 5 \mathrm{mM}$ range) and enzymes involved in either the GSH or Prx systems are highly concentrated in the matrix as well [103]. This is in contrast to $\alpha$-keto acids which usually occur in $\mu \mathrm{M}$ amounts in mitochondria $[104,105]$. It should also be noted that $\mathrm{H}_{2} \mathrm{O}_{2}$ quenching experiments with $\alpha$-keto acids use high $\mu \mathrm{M}$ to $\mathrm{mM}$ amounts of $\mathrm{H}_{2} \mathrm{O}_{2}$ and $\mathrm{mM}$ amounts of either a-keto acid, both of which are supraphysiological [105]. However, in a recent study Venditti et al were able to show that nonenzymatic $\mathrm{H}_{2} \mathrm{O}_{2}$ sequestration accounts for a significant fraction of $\mathrm{H}_{2} \mathrm{O}_{2}$ clearance in rat liver and heart mitochondria, with the latter dominating over the former [106]. This does point to the possibility that $a$-keto acids may fulfill an important role in $\mathrm{H}_{2} \mathrm{O}_{2}$ clearance in certain tissues. It is entirely probable that when mitochondria are facing high amounts of $\mathrm{H}_{2} \mathrm{O}_{2}$ a-keto acids can accumulate to sufficient concentrations to sequester $\mathrm{H}_{2} \mathrm{O}_{2}$. This may be especially relevant when antioxidant systems are being overwhelmed by oxidative stress. In addition Pdh and Odh are sensitive to deactivation by oxidative stress. Employment of $\alpha$-keto acids to quench $\mathrm{H}_{2} \mathrm{O}_{2}$ may also represent a more ancient form of antioxidant defense, potentially utilized by anaerobic systems, since it is reliant on Krebs cycle intermediates.

\section{Krebs Cycle Intermediates in Intra-and Intercellular Signaling}

G-protein coupled receptors (GPCR) are a ubiquitous super family of plasma membrane receptors found throughout nature and in various tissues [107]. These plasma membrane receptors fulfill a number of physiological functions which includes vision, smell, cell growth and division, neurological signaling, immune cell function, and many others [42]. In addition, GPCR are activated by a broad range of molecules and hormones including peptides, light, chemokines, odorants, purines, and lipids. GPCR harbors 7 membrane spanning a-helical regions which form a cavity that faces the extracellular space that serves as the ligand binding domain [108]. On the cytosolic side of the receptor binds to G-protein which is composed of three subunits; $\alpha, \beta$, and $\gamma$ [109]. Upon binding its cognate agonist, the receptor undergoes conformational changes resulting in an exchange of GDP for GTP in the Ga subunit. This subsequently leads to the activation and release of $\mathrm{G} \alpha$ from $G \beta \gamma$. While $\mathrm{G} \alpha$ induces the production of cAMP, a key intracellular signaling molecule, by adenylate cyclase, $G \beta \gamma$ activates phosphatidyl-inositol-3-kinase pathways. The GPCR super family has $>800$ members, most of which do not have a known ligand or function [42]. A little over a decade ago, two GPCR, GPR91 and GPR99, were identified as having high homology to purine binding GPCR but displayed little activation upon exposure to purines. Instead, GPR91 and GPR99 were found to be activated by succinate and 2-oxoglutarate [110]. In particular GPR91 displays high sensitivity towards succinic acid and is now referred to as succinate receptor 1 (SUCNR1) [110]. Thus, the efficiency of metabolite flux through the oxidative Krebs cycle can be communicated to other cells and tissues by using Krebs cycle intermediates in endocrine signaling.

The signaling functions of succinate and 2-oxoglutarate were originally described in detail for the HIF-1 pathway. 2-oxoglutarate serves as an important cofactor for prolyl hydroxylase (PHD) which hydroxylates HIF-1a tagging it for degradation which prevents activation of the hypoxic signaling cascade. On the other hand succinate has the opposite effect, inhibiting PHD resulting in HIF-1 assembly and expression of glycolytic genes [111]. Considering this intracellular signaling cascade has been reviewed extensively elsewhere it will not be discussed further here. Instead, major emphasis will be placed on the endocrine signaling functions of succinate and 2-oxoglutarate which act through SUCNR1 and GPR99, respectively. It can be assumed then that activation of either receptor by its cognate Krebs cycle intermediate inherently depends on the accumulation of succinate and 2-oxoglutarate in circulation which requires a slowing of the Krebs cycle. Messenger RNA encoding both receptors is expressed at low amounts in a number of tissues [110]. SUCNR1 and GPR99 also display some differential expression patterns where SUCNR1 is found in liver and spleen and to a lesser extent small intestine and GPR99 is located in substantial amounts in smooth muscle and testis [110]. Both receptors display the highest mRNA levels in kidney [110]. Most studies have focused on SUCNR1 and deciphering the impact of succinate signaling on various tissues. Accumulation of succinate in the bloodstream induces a concomitant increase circulating renin levels, a key component of the renin-angiotensin system that is required to modulate blood pressure [110]. Intravenous injection of succinate into rats led to an increase in renin which was also matched by an increase in blood pressure, a response that was absent in SUCNR1 deficient animals [110]. It has been reported that succinate and 2-oxoglutarate are present at $5 \mu \mathrm{M}$ and $25 \mu \mathrm{M}$, respectively, in circulation [112]. Succinate signaling is not reserved for the kidney and the modulation of blood pressure. Succinate is known to accumulate to even higher concentrations under stress or pathological conditions. For instance, ischemia and exercise can lead to an accumulation of up to $40 \mu \mathrm{M}$ succinate in the left ventricle and $173 \mu \mathrm{M}$ in circulation [113]. Succinate has been reported to accumulate to up to $1 \mathrm{mM}$ in liver perfusate following a bout of ischemia [114]. Quiescent hepatic stellate cells (HSC) do express ample amounts of SUCNR1 but upon activation expression of SUCNR1 decreases substantially [114]. Considering how rapidly succinate can accumulate in a stressed liver, it has been suggested that succinate accumulation and signaling through SUCNR1 serves as an early response towards hepatic stress and toxicity [114]. Succinate also prevents lipolysis in white adipose indicating its accumulation may be, in part, responsible for hypertrophying of white adipose in obesity, diabetes, and metabolic syndrome [115]. SUCNR1 has also been reported to play a role in blood and immune cells signaling where it is required for platelet aggregation, induction of hematopoietic progenitor cell proliferation, and immune cell function [115]. Thus, succinate serves as a crucial endocrine signaling molecule modulating blood pressure, immune and blood cell function, hepatic stellate cell activation, and lipolysis in response to stress. It is important to point out that very few studies have focused on 2-oxoglutarate-mediated endocrine signaling. In addition, although not discussed here, other important metabolites including lactate, ketone body 3 -hydroxy butyrate, and $\beta$-oxidation intermediate 3-hydroxy octanoate serve as ligands for orphan G-proteins GPR109A, 
GPR81, and GPR109B further illustrating the intimate link between metabolic flux and endocrine/paracrine signaling [116].

Metabolism of succinate serves as a major bottle neck in the oxidative Krebs cycle where the clearance of succinate inherently depends on the enzymatic activity of Sdh (Figure 1). This is in contrast to other metabolic steps in the Krebs cycle where metabolites can be diverted to other reactions (Figure 1). Thus, succinate could serve as an ideal signaling molecule, conveying the status of Krebs cycle flux to 1) the rest of the cell (intracellular signaling) and 2) other tissues (paracrine or endocrine stress signaling) since its metabolism or accumulation depends solely on Sdh activity (Figure 2). As indicated above Sdh is a major site for regulation of Krebs cycle flux playing a role in aerobic metabolism but also in the control of mitochondrial $\mathrm{O}_{2} \cdot / \mathrm{H}_{2} \mathrm{O}_{2}$ emission. Sdh is also modulated heavily by S-glutathionylation which is required to maintain its activity 117]. Bouts of ischemia-reperfusion in cardiac tissue inhibit Sdh activity via changes in S-glutathionylation of SdhA subunit [117]. Sdh is also inhibited by $\mathrm{H}_{2} \mathrm{O}_{2}$, another important redox signaling molecule [118]. Spatiotemporal changes in $\mathrm{H}_{2} \mathrm{O}_{2}$ serve as an important modulator of mitochondrial metabolism in response to fluctuations in nutrient metabolism and electron transfer efficiency. The temporary deactivation of Sdh by redox signaling mechanisms may allow succinate to accumulate to a sufficient quantity to act as a stress signaling molecule. Note that most redox modifications are rapid and reversible and thus the accumulation and clearance of succinate would also be expected to occur rapidly (Figure 2) $[34,66,116]$. Sdh can be targeted by irreversible modifications following oxidative stress and damage. For example, $\mathrm{Sdh}$ is covalently modified by 4 -HNE in diabetic myocardium $[119,120]$. Lashin et al. also identified SdhA subunit as the site for 4-HNE modification [120]. This is notable since SdhA is also a chief site for redox regulation of Sdh activity. Also reactions like S-glutathionylation protect thiols from irreversible oxidation by $\mathrm{H}_{2} \mathrm{O}_{2}$ or formation of Michael adducts with 4-HHE. Thus, irreversible inhibition of Sdh following oxidative damage to tissue can prolong succinate accumulation and signaling leading to development of pathologies such as hypertension, obesity, cardiomyopathy, and liver damage (Figure 2). It should not be surprising that the oxidative Krebs cycle can serve as signaling platform for modulation of various physiological processes since it is the central metabolic engine for life as we know it. Inherent to its central nature, the state of carbon flux through the cycle can be communicated to the rest of the cell or other cells via metabolites like succinate. In addition, the oxidative Krebs cycle is highly sensitive to deactivation by oxidative and environmental stress. Various Krebs cycle enzymes like Sdh can be deactivated by increased $\mathrm{H}_{2} \mathrm{O}_{2}$, oxidative damage, metal toxicity, or even robust changes in redox environment (e.g. GSH/GSSG) which leads to an accumulation of succinate and induction of various endocrine/ paracrine and intracellular signaling cascades. Sdh is also a key site for allosteric regulation. Oxaloacetate can also feedback and inhibit Sdh activity which would prompt an increase in succinate (Figure 2) [97,121]. Supplementation of mitochondria from brain or heart tissue with malate inhibits Sdh activity through formation of oxaloacetate

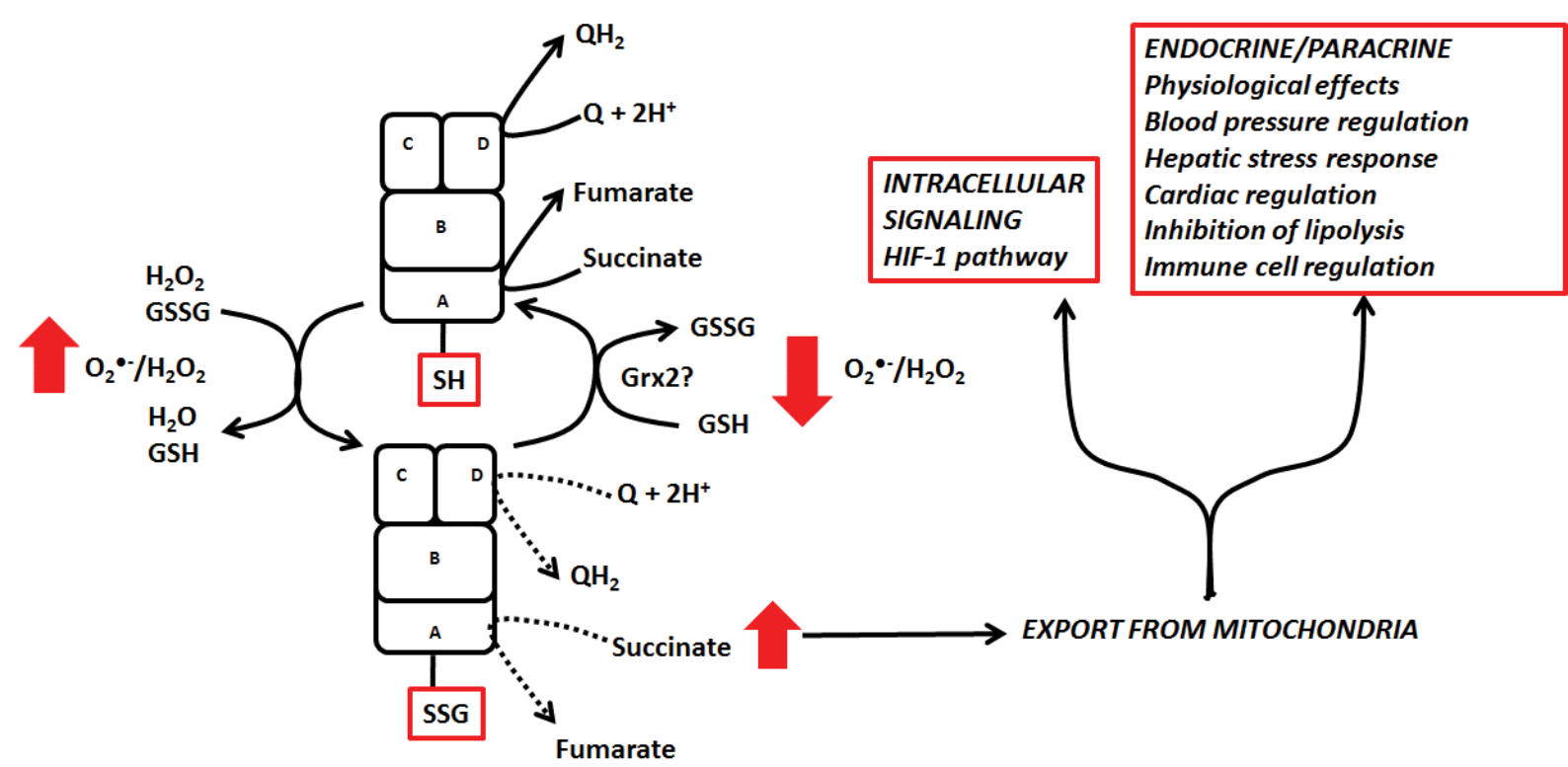

Figure 2: Succinate signals the state of carbon oxidation by the Krebs cycle: The function of succinate as a signaling molecule depends on its accumulation in mitochondria and subsequent export which depends on modulation of Sdh activity. Sdh can be reversibly modulated by allosteric inhibitors oxaloacetate and potentially malonate, a degradation production of oxaloacetate-mediated $\mathrm{H}_{2} \mathrm{O}_{2}$ sequestration. Oxaloacetate accumulation is dependent on Krebs cycle flux and the availability of acetyl-CoA. Sdh can also be targeted by redox signaling mechanisms, namely sulfenylation (SOH) and S-glutathionylation (SSG). In this potential mechanism, mitochondrial $\mathrm{O}_{2} \cdots / \mathrm{H}_{2} \mathrm{O}_{2}$ levels amass due to a slowing of nutrient oxidation and electron transfer reactions resulting in a shift in mitochondrial redox environment and the oxidation of protein cysteine thiols $(\mathrm{SH})$ on $\mathrm{SdhA}$ subunit. This limits Sdh activity allowing succinate concentrations to increase. Succinate is exported from mitochondria and utilized for intracellular or intercellular signaling. For intracellular signaling, succinate activates the HIF-1 signaling cascade which induces the expression of glycolytic genes. Succinate can also be exported from the cell and serve as a paracrine/endocrine signaling molecule. In this situation, succinate acts through SUCNR1 receptors to modulate various physiological processes including blood pressure, lipolysis in adipocytes, cardiomyocyte function, hepatic stress response, and immune cell function. Cysteine oxidation is likely reversed by glutaredoxin-2 (Grx2), a thiol oxidoreductase that deglutathionylates protein cysteine thiols. Here, once $\mathrm{O}_{2} \cdot-\mathrm{H}_{2} \mathrm{O}_{2}$ levels have dissipated, Grx2 removes glutathione from SdhA reactivating the enzyme complex. Reactivation results in the metabolism of succinate and prevention of its accumulation thus controlling succinate-mediated endocrine signaling. Note that prolonged deactivation of Sdh, in particular by irreversible covalent modifications, can result in sustained succinate signaling resulting in development or exacerbation of pathologies. 
$[122,123]$. The oxaloacetate-mediated control of Sdh activity has even been shown to modulate $\mathrm{Sdh}$-mediated $\mathrm{H}_{2} \mathrm{O}_{2}$ production which can have a significant effect on mitochondrial redox status and signaling patterns [122,123]. Accordingly, it can be proposed that succinate is an important endocrine hormone modulating physiological processes in response to fluctuations in oxidative Krebs cycle flux. However, prolonged inhibition of $\mathrm{Sdh}$ function and succinate accumulation could be a detriment since it can eventually lead to adipose hypertrophy, cardiomyopathy, hepatic stress, inflammation, and hypertension [42].

\section{Krebs Cycle Intermediates in Covalent Modification of Proteins}

Covalent modification of proteins (posttranslational modifications; PTM) plays a critical role in modulation of various cellular processes in response to intracellular and extracellular stimuli. The most well studied PTM is phosphorylation, a modification that inherently depends on cellular ATP production and nutrient metabolism. Other PTMs have shown to play a crucial role the control of protein function. For example, fluctuations in local redox environment due to changes in nutrient metabolism and $\mathrm{O}_{2} \cdot-/ \mathrm{H}_{2} \mathrm{O}_{2}$ handling can lead to redox modification of protein cysteine thiols [124]. There are a broad range of "redox switches" includes sulfenylation, sulfinylation, S-nitrosylation, and dithiol formation, that coalesce to modulate protein function in response to fluctuations in local redox environments [66]. Another important modification is acetylation which depends on the availability of acetyl-CoA. Since acetyl-CoA is critical metabolite generated as an end product of monosaccharide, fatty acid, ketone body, and amino acid metabolism, acetylation reactions are highly sensitive to nutrient status. However, acetylation/deacetylation reactions have been covered extensively and will not be discussed further here. Focus, instead, will be laid on succinyl-CoA and fumarate which have been shown to modify lysine and cysteine via succinylation and succination reactions. Succination proceeds via the Michael addition of fumaric acid to a protein cysteine thiol forming S-(2-succino) cysteine (2SC) [125]. Importantly, in contrast to succinylation which forms a biologically reversible covalent bond, succination reactions are generally irreversible [125]. In normal tissues and plasma there is a small fraction of proteins that are succinated. For example, $\sim 3 \%$ of the total albumin pool has been found to be succinated which increases dramatically during pathophysiological stress [126]. In streptozotocin-induced diabetic rats, the degree of total protein 2SC adducts formation in gastrocnemius muscle increases $\sim 3.5$ fold with glyceraldehyde-3-phosphate serving as a major target for modification $[127,128]$. This effectively limits G3PDH and glucose metabolism since the target cysteine for 2SC formation is required for catalysis. Acn has also been reported to be a target for succination which inhibits its function [129]. Fumarate can also deplete cellular GSH pools forming succinicGSH adducts which deplete GSH pools and alter cellular redox status [130]. Due to its irreversible nature, succination events have mostly been attributed to pathogenesis. An increased succinated proteome is associated with type 1 diabetes, obesity, and cancer [125,131]. For cancer, fumarate has been regarded as an "oncometabolite" since its accumulation correlates strongly with an increase in protein succination and the inhibition of protein function. Indeed, Fum is considered to be an anti-tumorigenic gene since it prevents carcinogenesis most likely via metabolism of fumarate [132]. Accumulation of fumarate is mostly associated with diminished mitochondrial function, specifically hyperpolarization of the mitochondrial inner membrane and slowing of electron transfer to $\mathrm{O}_{2}$ which effectively decreases carbon flux through the Krebs cycle [133]. Thus, succination is a consequence of perturbations in mitochondrial function and can be related to pathogenesis.

Unlike succination, succinylation is a regulatory modification that occurs in response to changes in carbon flux through the Krebs cycle. Addition of succinate to a lysine not only introduces a mass of $100 \mathrm{Da}$ to a protein but also introduces a negative charge on a positively charged lysine which, much like acetylation leads to conformational changes [115]. Intriguingly it has been found that mitochondrial sirtuin Sirt5 harbors protein lysine desuccinylase activity [134]. Bacteria also harbor a sirtuin-like protein which has been suggested to catalyzing protein desuccinylation [134]. Similarly, lysine succinylation has been identified in S. cerevisiae and D. melanogaster [134]. Considering that protein lysine succinylation persists throughout nature it can be considered to be an important PTM required to control protein function in response to fluctuations in oxidative Krebs cycle flux. Similar to succinate signaling through SUCNR1, succinylation communicates the state of carbon flux through the cycle to the rest of the cell. Decreases in Sdh activity have been linked to the accumulation of succinate and succinyl-CoA and the succinylation of lysine residues [115]. For instance, inhibition of Sdh with inhibitors like malonate or 3-nitropropionic acid increases succinylation of various proteins [135]. Succinylation is also highly responsive to energy state and nutrient oxidation. For example, protein lysine succinylation changes in response to fasting and postprandial conditions [135]. In fasting mice succinylation is more elevated where it has been suggested to be required for the modulation of lipolysis and glucose metabolism [135]. Also, a number of succinylation targets happen to be oxidative Krebs cycle enzymes. In the Krebs cycle Idh is succinylated specifically on Lys 199 and Lys242 which is required to modulate its activity [136]. Pdh is also targeted for succinylation as well as SdhA subunit [135]. Further, Sirt5 deficiency maintains Sdh in an active state indicating Sirt5 is required to desuccinylate SdhA and that succinylation positively regulates Sdh activity [137]. Although little information exists on how succinate and succinyl-CoA may accumulate it has been suggested that $\gamma$-aminobutyric acid (GABA) shunt pathway, which is modulated by LPS, may contribute to protein lysine succinylation [113]. Another possibility is that Sdh is activated and deactivated directly by fluctuations in local redox environment which, as mentioned previously, may be communicated via alterations in S-glutathionylation status. Indeed, the redox environment in the mitochondrial matrix is always in a state of flux due to the changes in $\mathrm{O}_{2} \bullet / \mathrm{H}_{2} \mathrm{O}_{2}$ and GSH and GSSG which are directly influenced by the efficiency of carbon flux through the Krebs cycle and electron transfer to $\mathrm{O}_{2}$ in the respiratory chain. With this in mind, modulation of Sdh directly by redox switches may be an important determinant for protein lysine succinylation (Figure 3). As mentioned above Sdh is modulated by various redox signals which could influence coalesce to modulate Sdh activity and succinyl-CoA levels leading to changes in the succinylated proteome (Figure 3). It would be important to consider though how Sirt5 may be activated/ deactivated in this mechanism. Sirt proteins, like Sirt1, are modulated by redox signaling where S-glutathionylation lowers its activity which can be reversed by glutaredoxins (Grx1 in cytosol or Grx2 in mitochondria) [138]. Sirt5 may be regulated in a similar manner; fluctuations in redox environment result in S-glutathionylation of Sirt5 allowing for protein succinylation (Figure 3). It is also important to point out that Sirt5 is controlled by the availability of NADH and NAD with the former serving as an inhibitor and the latter a substrate for desuccinylation where succinyl-ADP-ribose is formed after catalytic action [132]. Hence, in this hypothetical scheme the state of electron flux and nutrient oxidation can be communicated directly to other proteins throughout mitochondria and the cell via accumulation of succinyl- 


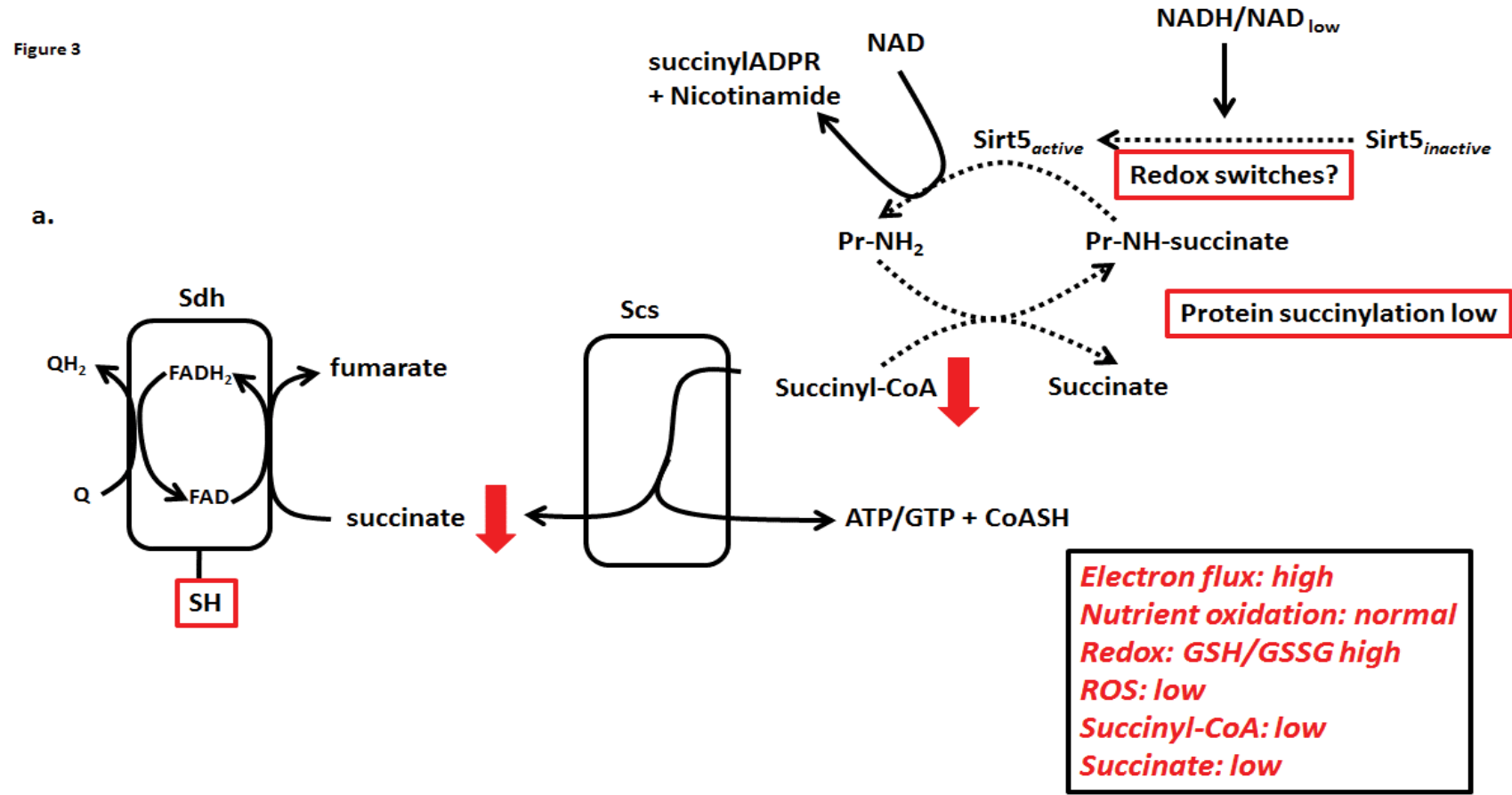

b.

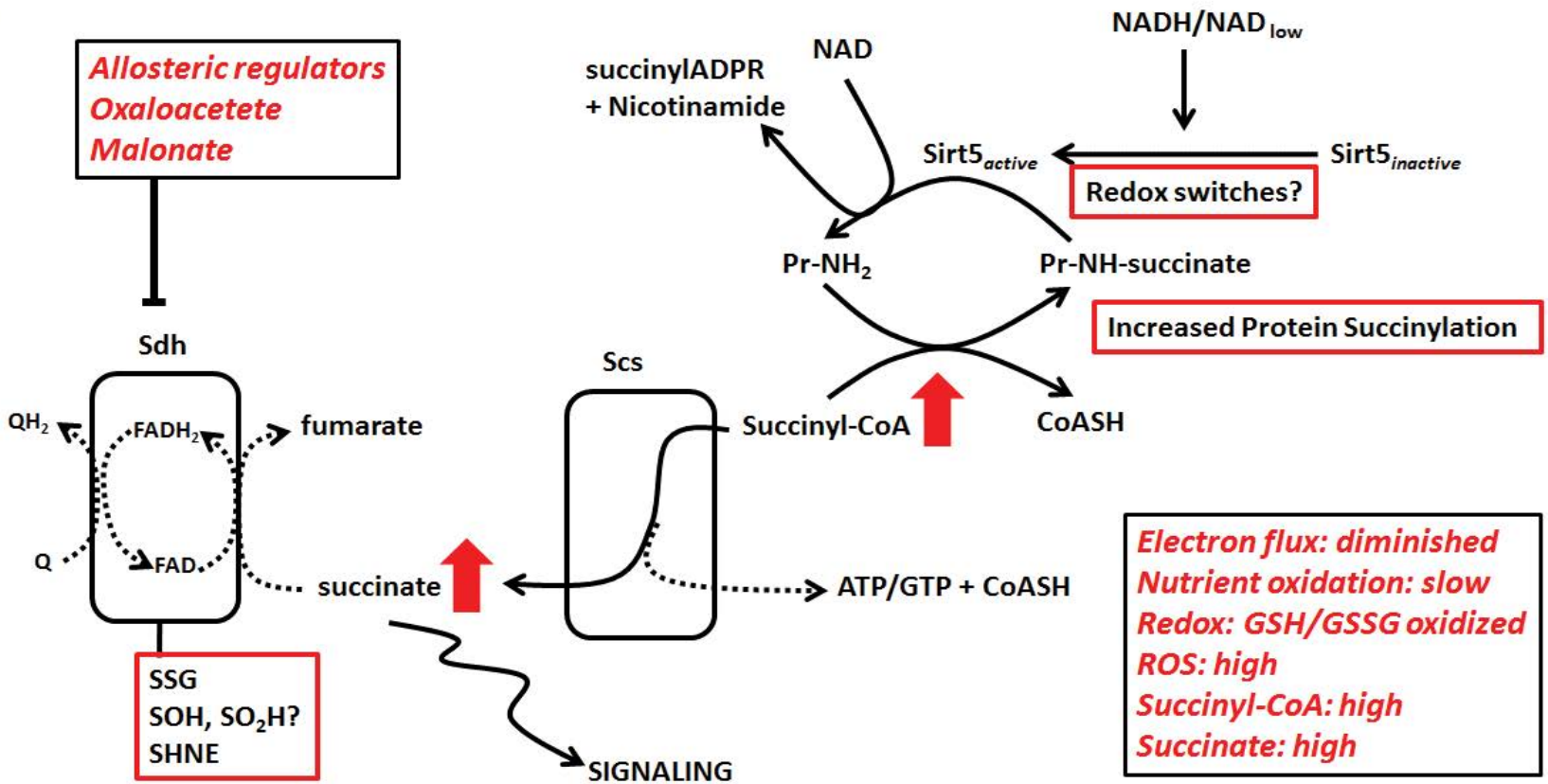

Figure 3: Modulation of mitochondrial protein function by protein succinylation reactions in response to variations in Krebs cycle flux and redox state: Succinylation reactions may be influenced by mitochondrial redox state considering the tight link between succinyl-CoA clearance, the efficiency of Krebs cycle flux, and the status of electron transfer reactions. a) When flux is high and transfer of electrons from nutrients to $\mathrm{O}_{2}$ is efficient, intramitochondrial $\mathrm{O}_{2} \cdot-/ \mathrm{H}_{2} \mathrm{O}_{2}$ levels are low and the mitochondrial GSH/GSSG pool is reducing maintaining Sdh in a reduced and active state. This prevents succinate and succinyl-CoA accumulation limiting the succinylation of proteins. Sirt5 would also limit protein succinylation. b) Decreased carbon flux and electron transfer efficiency leads to the increased production of $\mathrm{O}_{2}-/ \mathrm{H}_{2} \mathrm{O}_{2}$ which can either directly oxidize thiols forming sulfenic $(\mathrm{SOH})$ or sulfinic acids ( $\left.\mathrm{SO}_{2} \mathrm{H}\right)$ on Sdh or increase levels of GSSG leading to changes in protein S-glutathionylation (SSG). Prolonged $\mathrm{O}_{2} \cdot / \mathrm{H}_{2} \mathrm{O}_{2}$ production can lead to 4-HNE production and the irreversible deactivation of Sdh (SHNE). Thiol oxidation diminishes Sdh activity leading to the accumulation of succinate which prompts the accumulation of succinyl-CoA. This leads to an increase in protein succinylation in mitochondria and the further modulation of carbon flux and electron transfer reactions. Protein succinylation is reversed by Sirt5 which may be similarly modulated by fluctuations in the redox environment. 
CoA and the succinylation of protein targets (Figure 3). Inhibition of Sdh activity by either allosteric regulation, redox signaling, or potentially other mechanisms (gene expression, respirasome assembly) would 1) prompt succinate accumulation activating various signaling cascades and 2) increase succinyl-CoA levels which would modulate mitochondrial nutrient metabolism through reversible succinylation of proteins. It is also likely that redox switches and succinylation cross talk to modulate mitochondrial function in response to changes in nutrient flux, redox environment, and changes in the efficiency of electron transfer reactions.

\section{Concluding Remarks}

Over the past 75 years the scientific community has accumulated an exquisite breadth of knowledge on the oxidative Krebs cycle and its role in metabolism and physiology. However, it would only appear we have scratched the surface in terms of the absolute importance in biological systems. As shown here, the oxidative Krebs cycle can serve as a signaling platform and antioxidant defense system, a function inherently related to the removal of electrons from carbon for ATP production and biosynthetic reactions. Various elements of the oxidative Krebs cycle, including $\mathrm{O}_{2} \bullet / \mathrm{H}_{2} \mathrm{O}_{2}$ and carbon intermediates, signal to the rest of the cell and to other tissues the state and efficiency of carbon metabolism. Considering the potential danger associated with $\mathrm{O}_{2} \bullet / \mathrm{H}_{2} \mathrm{O}_{2}$ genesis, the oxidative Krebs cycle can be tailored to control ROS emission, either through control of enzyme function by redox signaling or the provision of NADPH and a-keto acids for antioxidant defense. These functions imbue the Krebs cycle with new roles; 1) endocrine stress signaling in response to a slowing of nutrient oxidation and increased mitochondrial $\mathrm{O}_{2} \bullet / \mathrm{H}_{2} \mathrm{O}_{2}$ production and 2) control mitochondrial metabolism and $\mathrm{O}_{2} \bullet / \mathrm{H}_{2} \mathrm{O}_{2}$ genesis in response to fluctuations in nutrient oxidation efficiency. In light of its fundamental function, it also stands to reason that Krebs cycle signaling is controlled by the status of electron transfer reactions and changes in redox environment (e.g. spatiotemporal fluctuations in reduced and oxidized glutathione levels).

\section{References}

1. Martin W, Russell MJ (2007) On the origin of biochemistry at an alkaline hydrothermal vent. Philosophical transactions of the Royal Society of London. Series B Biological sciences 362: 1887-1925.

2. Lane N (2014) Bioenergetic constraints on the evolution of complex life. Cold Spring Harbor perspectives in biology 6: a015982.

3. Lane N, Martin WF (2012) The origin of membrane bioenergetics. Cell 151 1406-1416.

4. Martin WF, Sousa FL, Lane N (2014) Evolution. Energy at life's origin. Science 344: 1092-1093.

5. Crowe SA, Dossing LN, Beukes NJ, Bau M, Kruger SJ, et al. (2013) Atmospheric oxygenation three billion years ago. Nature 501: 535-538.

6. Wallace DC (2010) Colloquium paper: bioenergetics, the origins of complexity, and the ascent of man. Proc Natl Acad Sci U S A 107 Suppl 2: 8947-8953.

7. Krebs HA (1948) The tricarboxylic acid cycle. Harvey lectures Series 44: 165199

8. Krebs HA, Salvin E, Johnson WA (1938) The formation of citric and alphaketoglutaric acids in the mammalian body. Biochem J 32: 113-117.

9. Chen XJ, Wang X, Butow RA (2007) Yeast aconitase binds and provides metabolically coupled protection to mitochondrial DNA. Proc Natl Acad Sci U S A 104: 13738-13743.

10. Chen XJ, Wang X, Kaufman BA, Butow RA (2005) Aconitase couples metabolic regulation to mitochondrial DNA maintenance. Science 307: 714-717.

11. Fernie AR, Carrari F, Sweetlove LJ (2004) Respiratory metabolism: glycolysis, the TCA cycle and mitochondrial electron transport. Current opinion in plant biology 7: 254-261

12. Krebs HA (1970) Rate control of the tricarboxylic acid cycle. Adv Enzyme Regul 8: $335-353$.

13. DeBerardinis RJ, Lum JJ, Hatzivassiliou G, Thompson CB (2008) The biology of cancer: metabolic reprogramming fuels cell growth and proliferation. Cell Metab 7: 11-20.

14. Akram M (2014) Citric acid cycle and role of its intermediates in metabolism Cell biochemistry and biophysics 68: 475-478.

15. Owen OE, Kalhan SC, Hanson RW (2002) The key role of anaplerosis and cataplerosis for citric acid cycle function. J Biol Chem 277: 30409-30412.

16. Mailloux RJ (2015) Teaching the fundamentals of electron transfer reactions in mitochondria and the production and detection of reactive oxygen species. Redox biology 4C: 381-398.

17. Krebs HA (1974) The discovery of carbon dioxide fixation in mammalian tissues. Molecular and cellular biochemistry 5: 79-97.

18. Fisher-Wellman KH, Lin CT, Ryan TE, Reese LR, Gilliam LA, et al (2015) Pyruvate dehydrogenase complex and nicotinamide nucleotide transhydrogenase constitute an energy consuming redox circuit. Biochem $\mathrm{J}$ 467: 271-280.

19. Hashimoto T Hussien R, Brooks GA (2006) Colocalization of MCT1, CD147, and LDH in mitochondrial inner membrane of L6 muscle cells: evidence of a mitochondrial lactate oxidation complex. Am J Physiol Endocrinol Metab 290: E1237-1244.

20. Goncalves RL, Rothschild DE, Quinlan CL, Scott GK, Benz CC, et al. (2014) Sources of superoxide/ $\mathrm{H}_{2} \mathrm{O}_{2}$ during mitochondrial proline oxidation. Redox biology 2: 901-909.

21. Flanagan WF, Holmes EW, Sabina RL, Swain JL (1986) Importance of purine nucleotide cycle to energy production in skeletal muscle. Am J Physiol 251: C795-802.

22. Mavri-Damelin D, Eaton S, Damelin LH, Rees M, Hodgson, HJ, Selden C(2007) Ornithine transcarbamylase and arginase I deficiency are responsible fo diminished urea cycle function in the human hepatoblastoma cell line HepG2. The international journal of biochemistry \& cell biology 39: 555-564.

23. Perevoshchikova IV, Quinlan CL, Orr AL, Gerencser AA, Brand MD (2013) Sites of superoxide and hydrogen peroxide production during fatty acid oxidation in rat skeletal muscle mitochondria. Free Radic Biol Med 61: 298-309.

24. Hou Y, Wang L, Ding B, Liu Y, Zhu, H, et al. (2011) Alpha-Ketoglutarate and intestinal function. Front Biosci 16: 1186-1196.

25. Nakagawa T, Lomb DJ, Haigis MC, Guarente L (2009) SIRT5 Deacetylates carbamoyl phosphate synthetase 1 and regulates the urea cycle. Cell 137: 560570

26. Muoio DM (2014) Metabolic inflexibility: when mitochondrial indecision leads to metabolic gridlock. Cell 159: 1253-1262.

27. Kasischke KA, Vishwasrao HD, Fisher PJ, Zipfel WR, Webb WW (2004) Neura activity triggers neuronal oxidative metabolism followed by astrocytic glycolysis. Science 305: 99-103.

28. Lemire J, Auger C, Mailloux R, Appanna VD (2014) Mitochondrial lactate metabolism is involved in antioxidative defense in human astrocytoma cells. J Neurosci Res 92: 464-475.

29. Williamson JR, Cooper RH (1980) Regulation of the citric acid cycle in mammalian systems. FEBS Lett 117 Suppl: K73-85.

30. Fisher-Wellman KH, Gilliam LA, Lin CT, Cathey BL, Lark DS, et al. (2013) Mitochondrial glutathione depletion reveals a novel role for the pyruvate dehydrogenase complex as a key $\mathrm{H} 2 \mathrm{O} 2$-emitting source under conditions of nutrient overload. Free Radic Biol Med 65: 1201-1208.

31. Sweetlove LJ, Heazlewood JL, Herald V, Holtzapffel R, Day DA, et al. (2002) The impact of oxidative stress on Arabidopsis mitochondria. The Plant journal: for cell and molecular biology 32: 891-904.

32. Bremer J, Davis EJ (1974) Citrate as a regulator of acetyl-CoA metabolism in liver mitochondria. Biochim Biophys Acta 370: 564-572.

33. Gardner PR, Raineri I, Epstein LB, White CW (1995) Superoxide radical and iron modulate aconitase activity in mammalian cells. J Biol Chem 270: 1339913405. 
Citation: Mailloux RJ (2015) Still at the Center of it All; Novel Functions of the Oxidative Krebs Cycle. Bioenergetics 4: 122. doi:10.4172/21677662.1000122

Page 12 of 14

34. Mailloux RJ, Willmore WG (2014) S-glutathionylation reactions in mitochondrial function and disease. Frontiers in cell and developmental biology 2: 68.

35. James AM Collins Y, Logan A, Murphy MP (2012) Mitochondrial oxidative stress and the metabolic syndrome. Trends Endocrinol Metab 23: 429-434.

36. Han D, Canali R, Garcia J, Aguilera R, Gallaher TK, et al. (2005) Sites and mechanisms of aconitase inactivation by peroxynitrite: modulation by citrate and glutathione. Biochemistry 44: 11986-11996.

37. Mailloux RJ, Harper ME (2010) Glucose regulates enzymatic sources of mitochondrial NADPH in skeletal muscle cells; a novel role for glucose-6phosphate dehydrogenase. Faseb J 24: 2495-2506.

38. Ehrlich RS (2000) Use of a bisubstrate inhibitor to distinguish between isocitrate dehydrogenase isozymes. Journal of enzyme inhibition 15: 265-272.

39. Guay C, Joly E, Pepin E, Barbeau A, Hentsch L, et al. (2013) A role for cytosolic isocitrate dehydrogenase as a negative regulator of glucose signaling for insulin secretion in pancreatic ss-cells. PLoS One 8: e77097.

40. Ramachandran N, Durbano M, Colman RF (1974) Kinetic isotope effects in the NAD- and NADP-specific isocitrate dehydrogenases of pig heart. FEBS Lett 49: 129-133.

41. Yankovskaya V, Horsefield R, Törnroth S, Luna-Chavez C, Miyoshi H, et al (2003) Architecture of succinate dehydrogenase and reactive oxygen species generation. Science 299: 700-704.

42. Deen PM, Robben JH (2011) Succinate receptors in the kidney. J Am Soc Nephrol 22: 1416-1422.

43. Quinlan C, Goncalves R, Hey-Mogensen M, Yadava N, Bunik V, et al. (2014) The 2-oxoacid dehydrogenase complexes in mitochondria can produce superoxide/hydrogen peroxide at much higher rates than complex I. The Journal of Biological Chemistry 289: 8312-8325.

44. Brand MD, Nicholls DG (2011) Assessing mitochondrial dysfunction in cells Biochem J 435: 297-312.

45. Verkhovskaya M, Bloch DA (2013) Energy-converting respiratory Complex I: on the way to the molecular mechanism of the proton pump. Int J Biochem Cell Biol 45: 491-511.

46. DeBerardinis RJ, Mancuso A, Daikhin E, Nissim I, Yudkoff M, et al. (2007) Beyond aerobic glycolysis: transformed cells can engage in glutamine metabolism that exceeds the requirement for protein and nucleotide synthesis. Proc Natl Acad Sci U S A 104: 19345-19350.

47. Phillips D, Aponte AM, French SA, Chess DJ, Balaban RS (2009) Succinyl-CoA synthetase is a phosphate target for the activation of mitochondrial metabolism. Biochemistry 48: 7140-7149.

48. Mather A, Pollock C (2011) Glucose handling by the kidney. Kidney Int Suppl: S1-6.

49. Corssmit E, Romijn J, Sauerwein H (2001) Review article: Regulation of glucose production with special attention to nonclassical regulatory mechanisms: a review. Metabolism: clinical and experimental 50: 742-755.

50. Han S, Lemire J, Appanna VP, Auger C, Castonguay Z, et al. (2013) How aluminum, an intracellular ROS generator promotes hepatic and neurological diseases: the metabolic tale. Cell Biol Toxicol 29: 75-84.

51. Funai K, Song H, Yin L, Lodhi IJ, Wei X, et al. (2013) Muscle lipogenesis balances insulin sensitivity and strength through calcium signaling. J Clin Invest 123: $1229-1240$

52. Ying $W(2008) N A D+/ N A D H$ and NADP+/NADPH in cellular functions and cell death: regulation and biological consequences. Antioxid Redox Signal 10: 179206.

53. Ballard FJ, Hanson RW (1967) The citrate cleavage pathway and lipogenesis in rat adipose tissue: replenishment of oxaloacetate. J Lipid Res 8: 73-79.

54. Vacanti NM, Divakaruni AS, Green CR, Parker SJ, Henry RR, et al. (2014) Regulation of substrate utilization by the mitochondrial pyruvate carrier. Mo Cell 56: 425-435.

55. Raffaella C, Francesca B, Italia F, Marina P, Giovanna L, et al. (2008) Alterations in hepatic mitochondrial compartment in a model of obesity and insulin resistance. Obesity (Silver Spring) 16: 958-964.

56. Seiler SE, Martin OJ, Noland RC, Slentz DH, DeBalsi KL, et al. (2014) Obesity and lipid stress inhibit carnitine acetyltransferase activity. J Lipid Res 55: 635-
644

57. Allen DG, Lamb GD, Westerblad H (2008) Skeletal muscle fatigue: cellular mechanisms. Physiol Rev 88: 287-332.

58. Brown GC (1992) Control of respiration and ATP synthesis in mammalian mitochondria and cells. Biochem J 284: 1-13.

59. Hardie DG (2004) The AMP-activated protein kinase pathway--new players upstream and downstream. J Cell Sci 117: 5479-5487.

60. Hardie DG (2004) AMP-activated protein kinase: the guardian of cardiac energy status. J Clin Invest 114: 465-468.

61. Tanabe T, Yamada M, Noma T, Kajii T, Nakazawa A (1993) Tissue-specific and developmentally regulated expression of the genes encoding adenylate kinase isozymes. J Biochem 113: 200-207.

62. Murphy MP (2009) How mitochondria produce reactive oxygen species. Biochem J 417: 1-13.

63. Massey V (1994) Activation of molecular oxygen by flavins and flavoproteins. $J$ Biol Chem 269: 22459-22462.

64. Riemer J, Schwarzländer M, Conrad M, Herrmann JM (2015) Thiol switches in mitochondria: operation and physiological relevance. Biol Chem 396: 465-482.

65. Hess M, Manson N (1984) Molecular oxygen: friend and foe - The role of the oxygen free radical system in the calcium paradox, the oxygen paradox and ischemia/reperfusion injury. Journal of molecular and cellular cardiology 16 969-985.

66. Mailloux RJ, Jin X, Willmore WG (2013) Redox regulation of mitochondria function with emphasis on cysteine oxidation reactions. Redox Biol 2: 123-139.

67. Gutteridge JM (1989) Iron and oxygen: a biologically damaging mixture. Acta Paediatr Scand Suppl 361: 78-85.

68. Finkel T (2012) From sulfenylation to sulfhydration: what a thiolate needs to tolerate. Sci Signal 5: 10.

69. Koo MS, Lee JH, Rah SY, Yeo WS, Lee JW, et al. (2003) A reducing system of the superoxide sensor SoxR in Escherichia coli. EMBO J 22: 2614-2622.

70. Woo HA, Yim SH, Shin DH, Kang D, Yu DY, et al. (2010) Inactivation of peroxiredoxin I by phosphorylation allows localized $\mathrm{H}_{2} \mathrm{O}_{2}$ accumulation for cell signaling. Cell 140: 517-528.

71. Caito S, Rajendrasozhan S, Cook S, Chung S, Yao H, et al. (2010) SIRT1 is a redox-sensitive deacetylase that is post-translationally modified by oxidants and carbonyl stress. FASEB J 24: 3145-3159.

72. Yun J, Finkel T (2014) Mitohormesis. Cell Metab 19: 757-766.

73. Boveris A, Oshino N, Chance B (1972) The cellular production of hydrogen peroxide. Biochem J 128: 617-630.

74. Quinlan C, Perevoshchikova I, Hey-Mogensen M, Orr A, Brand M (2013) Sites of reactive oxygen species generation by mitochondria oxidizing different substrates. Redox biology 1: 304-312.

75. Siebels I, Dröse S (2013) Q-site inhibitor induced ROS production of mitochondrial complex II is attenuated by TCA cycle dicarboxylates. Biochim Biophys Acta 1827: 1156-1164.

76. Bunik VI, Sievers C (2002) Inactivation of the 2-oxo acid dehydrogenase complexes upon generation of intrinsic radical species. Eur J Biochem 269: 5004-5015.

77. Starkov A, Fiskum G, Chinopoulos C, Lorenzo B, Browne S, et al. (2004) Mitochondrial alpha-ketoglutarate dehydrogenase complex generates reactive oxygen species. The Journal of neuroscience: the official journal of the Society for Neuroscience 24: 7779-7788.

78. Tretter L, Adam-Vizi V (2004) Generation of reactive oxygen species in the reaction catalyzed by alpha-ketoglutarate dehydrogenase. J Neurosci 24 7771-7778.

79. Stein LR, Imai S (2012) The dynamic regulation of NAD metabolism in mitochondria. Trends Endocrinol Metab 23: 420-428.

80. Cortassa S, O'Rourke B, Aon MA (2014) Redox-optimized ROS balance and the relationship between mitochondrial respiration and ROS. Biochem Biophys Acta 1837: 287-295.

81. Nulton-Persson A, Starke D, Mieyal J, Szweda L (2003) Reversible inactivation 
of alpha-ketoglutarate dehydrogenase in response to alterations in the mitochondrial glutathione status. Biochemistry 42: 4235-4242.

82. Crane D, Haussinger D, Graf $P$, Sies $H(1983)$ Decreased flux through pyruvate dehydrogenase by thiol oxidation during t-butyl hydroperoxide metabolism in perfused rat liver. Hoppe-Seyler's Zeitschrift fur physiologische Chemie 364 977-987

83. McLain AL, Szweda PA, Szweda L (2011) a-Ketoglutarate dehydrogenase: a mitochondrial redox sensor. Free Radic Res 45: 29-36.

84. Applegate M, Humphries K, Szweda L (2008) Reversible inhibition of alphaketoglutarate dehydrogenase by hydrogen peroxide: glutathionylation and protection of lipoic acid. Biochemistry 47: 473-478.

85. Imlay JA (2013) The molecular mechanisms and physiological consequences of oxidative stress: lessons from a model bacterium. Nat Rev Microbiol 11 : 443-454.

86. Cox AG, Winterbourn CC, Hampton MB (2009) Mitochondrial peroxiredoxin involvement in antioxidant defence and redox signalling. Biochem J 425: $313-$

87. Mailloux RJ, McBride SL, Harper ME (2013) Unearthing the secrets of mitochondrial ROS and glutathione in bioenergetics. Trends Biochem Sci 38: 592-602.

88. Hamilton RT, Walsh ME, Van Remmen H (2012) Mouse Models of Oxidative Stress Indicate a Role for Modulating Healthy Aging. J Clin Exp Pathol Suppl 4.

89. Johansson C, Lillig CH, Holmgren A (2004) Human mitochondrial glutaredoxin reduces $\mathrm{S}$-glutathionylated proteins with high affinity accepting electrons from either glutathione or thioredoxin reductase. J Biol Chem 279: 7537-7543.

90. Arnér ES, Holmgren A (2000) Physiological functions of thioredoxin and thioredoxin reductase. Eur J Biochem 267: 6102-6109.

91. Yang $H$, Ye D, Guan K, Xiong $Y$ (2012) IDH1 and IDH2 mutations in tumorigenesis: mechanistic insights and clinical perspectives. Clin Cancer Res 18: $5562-5571$

92. Lee $\mathrm{S}$, Jo $\mathrm{S}$, Lee $\mathrm{S}$, Koh $\mathrm{H}$, Song $\mathrm{H}$, et al. (2004) Role of NADP+-dependent isocitrate dehydrogenase (NADP+-ICDH) on cellular defence against oxidative injury by gamma-rays. Int J Radiat Biol 80: 635-642.

93. Koh HJ, Lee SM, Son BG, Lee SH, Ryoo ZY, et al. (2004) Cytosolic NADP+dependent isocitrate dehydrogenase plays a key role in lipid metabolism. J Bio Chem 279: 39968-39974

94. Dang L, White D, Gross S, Bennett B, Bittinger M, et al. (2009) Cancerassociated IDH1 mutations produce 2-hydroxyglutarate. Nature 462: 739-744.

95. Borger D, Goyal L, Yau T, Poon R, Ancukiewicz M, et al. (2014) Circulating oncometabolite 2-hydroxyglutarate is a potential surrogate biomarker in patients with isocitrate dehydrogenase-mutant intrahepatic cholangiocarcinoma. Clinical cancer research : an official journal of the American Association for Cancer Research 20: 1884-1890.

96. Obre E, Rossignol R (2015) Emerging concepts in bioenergetics and cancer research: metabolic flexibility, coupling, symbiosis, switch, oxidative tumors, metabolic remodeling, signaling and bioenergetic therapy. The international journal of biochemistry \& cell biology 59: 167-181.

97. Fedotcheva NI, Sokolov AP, Kondrashova MN (2006) Nonezymatic formation of succinate in mitochondria under oxidative stress. Free Radic Biol Med 41: 56-64.

98. Mailloux RJ, Bériault R, Lemire J, Singh R, Chénier DR, et al. (2007) The tricarboxylic acid cycle, an ancient metabolic network with a novel twist. PLoS One 2: e690.

99. Vlessis AA, Bartos D, Trunkey D (1990) Importance of spontaneous alphaketoacid decarboxylation in experiments involving peroxide. Biochem Biophys Res Commun 170: 1281-1287.

100. Shen H, Hu X, Liu C, Wang S, Zhang W, et al. (2010) Ethyl pyruvate protects against hypoxic-ischemic brain injury via anti-cell death and anti-inflammatory mechanisms. Neurobiology of disease 37: 711-722.

101. Desagher S, Glowinski J, Prémont J (1997) Pyruvate protects neurons against hydrogen peroxide-induced toxicity. J Neurosci 17: 9060-9067.

102. Thomas SC1, Alhasawi A, Appanna VP, Auger C, Appanna VD (2015) Brain metabolism and Alzheimer's disease: the prospect of a metabolite-based therapy. J Nutr Health Aging 19: 58-63.
103. Gutscher M, Pauleau AL, Marty L, Brach T, Wabnitz GH, et al (2008) Realtime imaging of the intracellular glutathione redox potential. Nat Methods 5 553-559.

104. Martin M, Ferrier B, Baverel G (1989) Transport and utilization of alphaketoglutarate by the rat kidney in vivo. Pflugers Arch 413: 217-224.

105. Vásquez-Vivar J, Denicola A, Radi R, Augusto O (1997) Peroxynitritemediated decarboxylation of pyruvate to both carbon dioxide and carbon dioxide radical anion. Chem Res Toxicol 10: 786-794.

106. Venditti P, Napolitano G, Di Meo S (2014) Role of enzymatic and nonenzymatic processes in $\mathrm{H}_{2} \mathrm{O}_{2}$ removal by rat liver and heart mitochondria. $J$ Bioenerg Biomembr 46: 83-91.

107. Oldham WM1, Hamm HE (2008) Heterotrimeric G protein activation by G-protein-coupled receptors. Nat Rev Mol Cell Biol 9: 60-71.

108. Lagerström MC1, Schiöth HB (2008) Structural diversity of G protein-coupled receptors and significance for drug discovery. Nat Rev Drug Discov 7: 339357.

109. Hillenbrand M, Schori C, Schöppe J, Plückthun A (2015) Comprehensive analysis of heterotrimeric G-protein complex diversity and their interactions with GPCRs in solution. Proc Natl Acad Sci U S A 112: E1181-1190.

110. He W, Miao FJ, Lin DC, Schwandner RT, Wang Z, et al. (2004) Citric acid cycle intermediates as ligands for orphan G-protein-coupled receptors. Nature 429: 188-193.

111. Selak MA Armour SM, Mackenzie ED, Boulahbel $H$, Watson DG, et al. (2005) Succinate links TCA cycle dysfunction to oncogenesis by inhibiting HIF-alpha prolyl hydroxylase. Cancer Cell 7: 77-85

112. Kushnir M, Komaromy-Hiller G, Shushan B, Urry F, Roberts W (2001) Analysis of dicarboxylic acids by tandem mass spectrometry. High-throughput quantitative measurement of methylmalonic acid in serum, plasma, and urine. Clinical chemistry 47: 1993-2002.

113. Sadagopan N, Li W, Roberds SL, Major T, Preston GM, et al. (2007) Circulating succinate is elevated in rodent models of hypertension and metabolic disease. Am J Hypertens 20: 1209-1215.

114. Correa PR, Kruglov EA, Thompson M, Leite MF, Dranoff JA, et al. (2007) Succinate is a paracrine signal for liver damage. J Hepatol 47: 262-269.

115. Mills E, O'Neill LA (2014) Succinate: a metabolic signal in inflammation. Trends Cell Biol 24: 313-320.

116. Ahmed K, Tunaru S, Offermanns S (2009) GPR109A, GPR109B and GPR81, a family of hydroxy-carboxylic acid receptors. Trends Pharmacol Sci 30: $557-562$

117. Chen Y, Chen C, Pfeiffer D, Zweier J (2007) Mitochondrial complex II in the post-ischemic heart: oxidative injury and the role of protein S-glutathionylation. J Biol Chem 282: 32640-32654.

118. Nulton-Persson AC, Szweda $L$ (2001) Modulation of mitochondrial function by hydrogen peroxide. J Biol Chem 276: 23357-23361.

119. Murphy MP (2012) Mitochondrial thiols in antioxidant protection and redox signaling: distinct roles for glutathionylation and other thiol modifications. Antioxid Redox Signal 16: 476-495

120. Lashin OM, Szweda PA, Szweda L, Romani AM (2006) Decreased complex II respiration and HNE-modified $\mathrm{SDH}$ subunit in diabetic heart. Free Radic Biol Med 40: 886-896.

121. Wojtczak L, Wojtczak AB, Ernster L (1969) The inhibition of succinate dehydrogenase by oxalacetate. Biochim Biophys Acta 191: 10-21.

122. Zoccarato F, Miotto C, Cavallini L, Alexandre A (2011) The control of mitochondrial succinate-dependent $\mathrm{H} 2 \mathrm{O} 2$ production. J Bioenerg Biomembr 43: $359-366$

123. Zoccarato F, Cavallini L, Alexandre A (2009) Succinate is the controller of $\mathrm{O}_{2}-/ \mathrm{H}_{2} \mathrm{O}_{2}$ release at mitochondrial complex I: negative modulation by malate, positive by cyanide. J Bioenerg Biomembr 41: 387-393.

124. Dalle-Donne I, Rossi R, Colombo G, Giustarini D, Milzani A (2009) Protein S-glutathionylation: a regulatory device from bacteria to humans. Trends Biochem Sci 34: 85-96. 
Citation: Mailloux RJ (2015) Still at the Center of it All; Novel Functions of the Oxidative Krebs Cycle. Bioenergetics 4: 122. doi:10.4172/21677662.1000122

Page 14 of 14

125. Merkley ED, Metz TO, Smith RD, Baynes JW, Frizzell N (2014) The succinated proteome. Mass Spectrom Rev 33: 98-109.

126. Alderson NL, Wang Y, Blatnik M, Frizzell N, Walla MD, et al. (2006) S-(2Succinyl) cysteine: a novel chemical modification of tissue proteins by a Krebs cycle intermediate. Arch Biochem Biophys 450: 1-8.

127. Blatnik M, Thorpe SR, Baynes JW (2008) Succination of proteins by fumarate: mechanism of inactivation of glyceraldehyde-3-phosphate dehydrogenase in diabetes. Ann N Y Acad Sci 1126: 272-275.

128. Blatnik M, Frizzell N, Thorpe S, Baynes J (2008) Inactivation of glyceraldehyde-3-phosphate dehydrogenase by fumarate in diabetes: formation of S-(2-succinyl)cysteine, a novel chemical modification of protein and possible biomarker of mitochondrial stress. Diabetes 57: 41-49.

129. Ternette N, Yang M, Laroyia M, Kitagawa M, O'Flaherty L, et al. (2013) Inhibition of mitochondrial aconitase by succination in fumarate hydratase deficiency. Cell Rep 3: 689-700.

130. Zheng L, Cardaci S, Jerby L, Mackenzie E, Sciacovelli M, et al. (2015) Fumarate induces redox-dependent senescence by modifying glutathione metabolism. Nature communications 6: 6001.

131. Yang M, Ternette N, Su H, Dabiri R, Kessler BM, et al. (2014) The Succinated
Proteome of FH-Mutant Tumours. Metabolites 4: 640-654.

132. Yang M, Soga T, Pollard PJ, Adam J (2012) The emerging role of fumarate as an oncometabolite. Front Oncol 2: 85.

133. Bénit $P$, Letouzé $E$, Rak M, Aubry L, Burnichon N, et al. (2014) Unsuspected task for an old team: succinate, fumarate and other Krebs cycle acids in metabolic remodeling. Biochim Biophys Acta 1837: 1330-1337.

134. Papanicolaou KN, O'Rourke B, Foster DB (2014) Metabolism leaves its mark on the powerhouse: recent progress in post-translational modifications of lysine in mitochondria. Front Physiol 5: 301.

135. Park J, Chen Y, Tishkoff DX, Peng C, Tan M, et al. (2013) SIRT5-mediated lysine desuccinylation impacts diverse metabolic pathways. Mol Cell 50: 919930.

136. Du J, Zhou Y, Su X, Yu JJ, Khan S, et al. (2011) Sirt5 is a NAD-dependent protein lysine demalonylase and desuccinylase. Science 334: 806-809.

137. Tan M, Peng C, Anderson K, Chhoy P, Xie Z, et al. (2014) Lysine glutarylation is a protein posttranslational modification regulated by SIRT5 Cell Metabolism 19: 605-617.

138. Bräutigam L, Jensen LD, Poschmann G, Nyström S, Bannenberg S, et al. (2013) Glutaredoxin regulates vascular development by reversible glutathionylation of sirtuin 1. Proc Natl Acad Sci U S A 110: 20057-20062. 